\title{
Ueber kapillarelektrische Vorgänge in der lebenden Zelle.
}

\author{
Von Alexander Nathansohn (z. Zt. Dresden). \\ (Eingegangen am 24. Oktober 1919.)
}

\section{Kapillarelektrische Oxydation im Protoplasma.}

In dieser Arbeit soll gezeigt werden, daß die elektrischen Potentialdifferenzen im lebenden Protoplasma nicht allein, wie wiederholt betont worden ist, Wasserbewegung und Konzentrationsänderungen bewirken können; daB ihr Auftreten vielmehr auch von elektrolytischer Wasserzersetzung begleitet ist, und so durch Erzeugung naszierenden Wasserstoffs und Sauerstoffs tief in den fundamentalsten aller Lebensvorgänge, die physiologische Oxydation, eingreift.

Bis in die Tage von Lavoisier gehen die Versuche zurück, diese Erscheinung begreiflich zu machen und zu erklären, wie es kommt, daß Eiweißkörper, Fette und Kohlehydrate, also reaktionsträge Substanzen, im Organismus durch den ebenso trägen atmosphärischen Sauerstoff mit beträchtlicher Geschwindigkeit völlig oxydiert werden. Eine Erklärung dafür erhalten wir auch nicht, wenn wir berücksichtigen, daß die Oxydation in der Regel nicht die genannten Stoffe selbst, sondern ihre Spaltungsprodukte ergreift. Herzfeld und Klinger ${ }^{1}$ ) haben deren Oxydationsgeschwindigkeit geprüft, indem sie $z$ wölf Stunden lang durch 0,1 prozentige Lösungen verschiedener in Betracht kommender Substanzen einen kohlesäurefreien Luftstrom leitetén. $20 \mathrm{ccm}$ Milchsäurelösung ergaben in derartigen Versuchen $3,6 \mathrm{mg}$ Kohlensäure. Demgegenüber verbraucht z. B. $1 \mathrm{~g}$ lebender Katzenleber in einer Stunde $3 \mathrm{mg}$ Sauerstoff: das bedeutet eine Reaktionsgeschwindigkeit, die etwa $300 \mathrm{mal}$ so grob is; wie die der Milchsäurelösung.

1) E. Herzfeld u. R. Klinger, Biochem. Zeitschr. 93, 324 (1919). 
Nun hat zweifellos die Enzymforschung manches zur Klärung des Atmungsproblems beigetragen und namentlich in den letzten Jahren eine Anzahl von fermentativen Oxydationen kennen gelehrt, die sich auf wichtige Stoffwechselprodukte beziehen ${ }^{1}$ ). Hierher ist vor allem die Gruppe der sogenannten Reduktasen zu rechnen, Fermente, von denen Schardinger eines in der Milch entdeckt hat und, die bei allen Organismen weit verbreitet sind; den Untersuchungen von $\mathrm{Bach}$ und von Wieland $\mathrm{d}^{2}$ ) verdanken wir vor allem ihre nähere Kenntnis. Es hat sich dabei gezeigt, daß sie imstande sind, verschiedene Aldehyde zu den entsprechenden Säuren zu oxydieren und sich dabei mannigfacher Sauerstoffquellen zu bedienen: entweder des atmosphärischen Sauerstoffs oder gebundenen, indem sie bei der Oxydation des Aldehyds Methylenblau, Chlorate oder Nitrate reduzieren. Da nun Aldehyde im abbauenden Stoffwechsel eine wichtige Rolle spielen, liegt die große Bedeutung dieses Ferments auf der Hand. Vor allem hat aber Wieland gezeigt, dab es identisch ist mit der sogenannten Aldehydmutase, jenem Enzym, das die Cannizzaro'sche Umlagerung beschleunigt, der Reaktion bei der je zwei Aldehydmoleküle nach folgender Gleichung aufeinander wirken:

$$
\mathrm{R}_{1} \mathrm{COH}+\mathrm{R}_{2} \mathrm{COH}+\mathrm{H}_{2} \mathrm{O}=\mathrm{R}_{1} \mathrm{COOH}+\mathrm{R}_{2} \mathrm{CH}_{2} \mathrm{OH}
$$

worin $R_{1}$ mit $R_{2}$ identisch sein kann. Es wird also hier ein Aldehydmolekül auf Kosten eines anderen oxydiert, welch letzteres hier die Rolle der Sauerstoffquelle spielt und demnach das Methylenblau, Chlorat oder Nitrat vertritt. Da wir nun wissen ${ }^{3}$ ), daß die Cannizzaro'sche Umlagerung in der alkoholischen Gärung eine bedeutende Rolle spielt, so haben wir in dem Aldehydferment ein Enzym vor uns, das sowohl für die normale als für die intramolekulare Atmung in Betracht kommt.

Ein anderes, sehr verbreitetes Oxydationsferment, die Tyrosinase, bewirkt wie die Untersuchungen von Chodat und Schweitzer ${ }^{4}$ ) gelehrt haben, die oxydative Desaminierung der Aminosäuren unter Abspaltung von Kohlensäure und Ammoniak, und Bildung von Aldehyd nach der Reaktionsgleichung:

1) O. Warburg, Arch. f. d. ges. Physiol. 154, 599 (1913).

2) A. B a c h, Biochem. Zeitschr. 31, 443 (1911); 33, 282 (1911); 38, 154 (1912); 52, 412 (1913); 58 (1913); H. Wi el and, Ber. d. Deutsch. chem. Ges. 47, 2085 (1915).

3) .Vgl. C. Neuberg, die Gärungsvorgänge und der Zuckerumsatz in der Zelle (Jena 1913), S. 9 ff.; C. Neuberg u. E. Reinfurth, Biochem. Zeitschr. 89 (1918).

4) R. Chodat u. K. Schweitzer, Arch. sc. phys. et nat. [4] 3, 140; Schweitzer, Biochem. Zeitschr. 78, 37 (1916). 
$\mathrm{RCH} \cdot \mathrm{NH}_{2} \cdot \mathrm{COOH}+\mathrm{O}=\mathrm{RCOH}+\mathrm{CO}_{2}+\mathrm{NH}_{3}$, also einen Prozeß, der für die Verarbeitung der Abbauprodukte von Eiweißkörpern von allergrößter Bedeutung ist; und die oxydative Spaltung und Desaminierung der Purinkörper, der Produkte des Nukleïnstoffwechsels, durch Fermente ist schon seit längerer Zeit bekannt.

In diesem Zusammenhange wären ferner noch zu nennen jene Oxydationsfermente, die zweibasische Säuren, wie Bernsteinsäure, angreifen. Alle diese Reaktionen bilden Glieder der Kette, die den oxydativen Abbau der Nahrungsstoffe darstellt; sie können teilweise ineinander eingreifen: wenn z. B. aus Oxysäuren oder Aminosäuren Aldehyde entstehen, so wird das Aldehydferment sie zu der entsprechenden Säure weiter oxydieren und so aufs Neue eine Oxysäure, aber mit verkürzter C-Kette liefern, die dann abermals der oxydativen Spaltung unterliegen kann.

So kann es heute zwar noch nicht für erwiesen, aber doch für sehr wohl möglich gelten, daß für alle Teilprozesse des oxydativen Abbaus Enzyme vorhanden sind; trotzdem ist es noch nicht gelungen, den gesamten Ablauf einer dieser Reaktionsketten mit Hilfe von Organextrakten oder leblosen Organpräparaten zu reproduzieren; vielmehr haben die darauf gerichteten Bemühungen gelehrt, $\mathrm{da} B$ das Atmungsproblem in seinem vollen Umfange auf dem Wege der Enzymforschung überhaupt nicht gelöst werden kann, denn eine ganze Reihe von Untersuchungen, namentlich von $\mathrm{Warbu \textrm {ug } ^ { 1 } )}$ und von $\mathrm{B}$ attelli und $S$ ter $\mathrm{n}^{2}$ ) haben gezeigt, daß auBer den bekannten und den vielleicht vorhandenen, aber noch nicht aufgefundenen Enzymen noch etwas anderes eine wesentliche Rolle spielt, nämlich die Struktur des Protoplasmas, die einen entscheidenden Einfluß auf die Geschwindigkeit der physiologischen Oxydation hat.

Es erwies sich in Warburgs Versuchen mit Vogelblutzellen, daß nicht die grobe Zellstruktur das Entscheidende ist. Wurden derartige Elemente zum Gefrieren gebracht und dann wieder rasch aufgetaut, so trat der flüssige Protoplasmainhalt aus, und in solchem Material waren keine Zellgrenzen mehr zu sehen; seine Atmung aber war genau so intensiv wie die der intakten Zellen. Wurde diese Masse scharf zentrifugiert, so zeigte sich die Atmung an das die Strukturteile enthaltende. Sediment gebunden. Erfolgte aber durch

1) Vgl. O. Warburg, Ueber die Wirkung der Struktur auf chemische Vorgänge in den Zellen (Jena 1913); ders., Erg. d. Physiologie 14 (1914).

2) L. Stern, Der Mechanismus der Oxydationsvorgänge im Tierkörper (Jena), 194; F. Batte11i u. L. Stern, Biochem. Zeitschr. 67, 443 (1914). 
Gefrierenlassen und intensives Zerreiben Zerstörung der feineren Plasmastruktur, so sank die Atmungsintensität oft bis zur UnmeBbarkeit herab.

Dasselbe lehren Versuche von Battelli und Stern an verschiedenen Säugetierorganen. Verglichen wurde hier die Atmung von Material, das in der Fleischhackmaschine grob zerkleinert war, mit solchem, das man kurze Zeit in einer sehr intensiv wirkenden Mühle behandelt hatte. Auch hier zeigte sich, daB die Atmung mit fortschreitender Zerstörung abnahm, ebenso wie die Fähigkeit der Substanz, zugesetzte Zitronen- oder Apfelsäure zu oxydieren.

In gleicher Weise, wie die bisher betrachteten Vorgänge der physiologischen Oxydation, ist auch die alkoholische Gärung von der Zellstruktur abhängig. Diese Reaktion, die bekanntlich aus einer Kette ineinandergreifender Spaltungen und gekoppelter Oxydations- und Reduktionsprozesse besteht, läßt sich qualitativ an leblosem Material reproduzieren, indem man entweder die Hefezellen zerreibt und unter starkem Druck auspreßt, oder mit Azeton tötet und trocknet; aber alle diese Prozeduren bewirken einen wesentlichen Abfall der Intensität des Umsatzes: niemals gelingt es, auf diesem Wege ein Material herzustellen, von der gleichen Gärkraft wie die der lebenden Zellen, die zu seiner Bereitung dienten $\left.{ }^{1}\right)$.

Battelli und Stern diskutieren kurz die verschiedenen Möglichkeiten, die Abhängigkeit der Atmungsintensität von der Plasmastruktur zu erklären: So z. B., daß bestimmte Substanzen im lebenden Protoplasma lokalisiert sind und erst bei der Strukturzerstörung mit den Fermenten in schädigende Berührung kommen; oder daß das Wasser resp. die Salzlösungen, die bei der Bereitung des Materials Verwendung finden, diese Schädigung bewirken; oder endlich, daß in der physikalischen Zellstruktur Momente liegen, die fördernd auf die physiologische Oxydation unter dem Einfluß der Enzyme wirken.

Bei Beurteilung dieser Frage ist noch ein ganz anderer Gesichtspunkt ins Auge zu fassen, nämlich das Problem, auf welchem Wege im lebenden Organismus die Transformation der Energie erfolgt. Da doch die Atmung die Kraftquelle alles Lebens ist, muB diese Transformation in der mannigfachsten Weise erfolgen; das wäre aber nur in beschränktem Maße möglich, wenn die Atmung ohne an die Struktur gebunden zu sein, vor sich ginge, wie etwa

1) Vgl. Max Rubner, Die Ernährung der Hefezelle bei der alkoholischen Gärung (Leipzig 1913), S. 63; O. Wa rburg, Wirkung der Struktur usw., S. 14. 
irgend eine Enzymreaktion in wässeriger Lösung. Zwar bilden in einer ganzen Anzahl von Teilprozessen des Lebens Konzentrationsdifferenzen, durch lokalisierte Stoffwechselprozesse erzeugt, die treibende Kraft $^{1}$ ). In diesen Fällen ist für die energetische Verwertung der chemischen Reaktion nur der Ort des Entstehens von Bedeutung, die Art ihres Zustandekommens aber gleichgültig. Betrachtet man jedoch die Lebenserscheinungen in ihrer gesamten Verkettung, so bleibt stets in ihrem Energiewechsel ein durch bloße Konzentrationsunterschiede nicht erklärbarer Rest übrig. Auf diese Dinge kommen wir im zweiten Teil dieser Arbeit ausführlicher zurück; hier sei bloß erwähnt, daß dieser Rest sowohl bei osmotischen als auch bei chemischen Arbeitsleistungen auftritt, daß er sich aber in den beiden letzteren Fällen mitunter in letzter Linie auf osmotische Arbeit zurückführen läßt²). Die Möglichkeit einer an die Struktur gebundenen Transformation muß nun die Theorie der Atmung ebenso gut erklären, wie die Beschleunigung träger Verbrennungen, und darum habe ich bereits in dem soeben erwähnten Buch (S. 395) ausdrücklich betont, daß sogar die Kenntnis aller Enzyme, die für jede einzelne Reaktionsstufe des abbauenden Stoffwechsels in Betracht kommen, noch keine völlige Lösung des Atmungsproblems bilden würde: dessen Kern liegt vielmehr, auch von diesem Gesichtspunkt aus betrachtet, in der Frage nach der Art, wie die Atmung an die lebende Struktur geknüpft ist.

$\mathrm{Zu}$ dem gleichen Ergebnis kommt Rubner (loc. cit. S. 50) bei seinén Untersuchungen über die Wärmeproduktion gärender Hefe und er setzt auseinander, daß die rein enzymatische Gärung das Energiebedürfnis der Hefezelle nicht befriedigen kann. Er nimmt daneben einen vitalen Gärungsprozeß an, der zwar auch mit Hilfe von Enzymen erfolgt, bei dem aber irgend eine Verknüpfung mit der Plasmastruktur vorhanden ist.

Beide Seiten des Atmungsproblems, die Frage nach den Ursachen der physiologischen Verbrennung, sowie nach den Wegen der Energietransformation, verlangen also in erster Linie Klarheit über das Wesen der Struktur, an die die Lebenstätigkeit geknüpft ist. Unabhängig von jeder besonderen Annahme können wir sie im Allgemeinen dahin charakterisieren, daß das Plasma ein ungeheures Oberflächensystem darstellt, mag es im Einzelnen aus Granulis, aus Fibrillen oder aus Waben

1) Vgl. W. Pfeffer, Studien zur Energetik der Pflanze. Abh. d. K. S. Ges. d. Wiss. Math.-phys. K1. 31 (1892).

2) A. Nathansohn, Der Stoffwechsel der Pflanze (Leipzig 1910), S. 395 ff. 
aufgebaut sein. Um uns ein ungefähres Bild von der GröBenordnung zu machen, nehmen wir z. B. an, $1 \mathrm{ccm}$ plasmatischer Substanz bestände aus durchaus würfelförmigen Waben von $1 \mu$ Seite; dann kämen als Wabenoberflächen in Betracht 6.10000 Flächen von $1 \mathrm{qcm}$, ssgesamt also eine Fläche von $6 \mathrm{qm}$. Eine solche Struktur wäre aber verhältnismäßig grob; nehmen wir dafür submikroskopische Dimensionen an, also z. B. Waben von $0,1 \mu$ Seite, so würde die berechnete Oberfläche auf $60 \mathrm{qm}$ steigen. Da nun die Atmung natürlich auf die ganze lebendige Substanz verteilt ist, so würde sich die Reaktion auf der gesamten Strukturoberfläche abspielen. Das ist nicht ohne Bedeutung ${ }^{1}$, denn die Oberfläche ist ja nicht nur eine materielle Grenze : sie ist auch der Sitz von Potentialsprüngen, die auf die Reagenzien der Atmung wirken müssen, sobald diese in ihren Bereich kommen. Solcher Potentiale gibt es zweierlei: mechanische und elektrische; und daf ich in diesen letzteren und der durch sie bewirkten Elektrolyse die Lösung des Atmungsproblems erblicke, habe ich den einleitenden Worten bereits angedeutet.

Wir gehen bei unserer weiteren Betrachtung am besten von der elektrolytischen Wasserzersetzung unter gewöhnlichen Verhältnissen aus. Zur Durchführung dieses Prozesses etwa bei $18^{\circ} \mathrm{C}$ und einer Atm. Druck bringen wir ein Paar metallischer Elektroden auf eine Spannungsdifferenz von $>1,237 \mathrm{~V}$ (in Praxis wenigstens $0,2 \mathrm{~V}$ mehr). Aber weder diese relativ große Spannung, noch die Anwesenheit metallischer Elektroden ist in Wirklichkeit für die Durchführung des Prozesses unentbehrlich.

Was zunächst die angegebene Spannung betrifft, so ist sie eigentlich ein Zufallswert, der von der Höhe des herrschenden Druckes abhängt. Erteilen wir den Elektroden ein geringeres Potential, so beginnt unter allen Umständen die Elektrolyse, aber die Produkte bleiben zunächst (physikalisch oder chemisch) an die Elektroden gebunden, denen sie durch ihre Neigung, unter Entnahme entsprechender Ladungen $\mathrm{H}$ oder $\mathrm{OH}^{\prime}$ - Ionen zu bilden, eine Spannung erteilen, die der von außen angelegten entgegengesetzt ist. Mit steigender Konzentration der Elektrolysenprodukte an den. Elektroden wächst diese Gegenspannung, bis sie schließlich die äußere aufhebt, und dann kommt die Elektrolyse żur Ruhe, der Strom hört auf; die Elektroden aber haben sich mit $\mathrm{O}$ und $\mathrm{H}$ beladen. Steigern wir nun die angelegte Spannung,

1) Ueber die allgemeine Bedeutung der Oberflächen für den Stoffwechsel vgl. W. Pfeffer, Pflanzenphysiologie 2. Aufl, 1, 63 (1897). 
so wächst die Endkonzentration der Gasbeladung, und schließlich kann sie so groß werden, daß die Elektrode die Gase nicht mehr festhält, und diese in Form von Bläschen entweichen. Der Spannungswert bei dem dieser Grenzzustand erreicht wird, hängt vom Atmosphärendruck ab und verringert sich mit dessen Abnahme.

Eine minimale Elektrolyse läßt sich schon bei einer Klemmenspannung von $0,005 \mathrm{~V}$ nachweisen ${ }^{1}$ ), führt aber nur zu äußerst geringen Beladungen mit $\mathrm{H}$ und $\mathrm{O}$. Bei Schließung einer solchen Kette würde ein kurz dauernder Stromstoß erfolgen, bis die Elektroden ihre Gleichgewichtsbeladung gewonnen haben. Streng genommen steht auch dann der ProzeB nicht still, es verbleibt vielmehr ein minimaler aber dauernder Reststrom, der daher rührt, daß die Gase von den Elektroden hinwegdiffundieren und in gleichem Maße durch erneute Wasserzersetzung ersetzt werden. Wir können aber die anfängliche Elektrolysengeschwindigkeit und damit auch den anfänglichen Strom bei niedriger Spannung dauernd aufrecht erhalten, wenn wir nur dafür sorgen, daß die Elektrolysenprodukte außer durch langsame Diffusion durch einen chemischen Prozeß entfernt werden, und dazu müssen wir die Anode, an der sich Sauerstoff entwickelt in eine reduzierende, die wasserstoffbildende Kathode in eine oxydierende Lösung tauchen. Diese Lösungen verbrauchen die Zersetzungsprodukte an den Elektroden und sorgen damit für deren dauernde Depolarisation.

Tauchen z. B. beide Elektroden in eine Lösung von Chinhydron, einer Verbindung je eines Moleküls Chinon und Hydrochinon ${ }^{2}$ ), so wird diese an der Anode durch den Elektrolyt-O oxydiert, an der Kathode durch den naszierenden $\mathrm{H}$ reduziert. Nach den vorliegenden Messungen würde unter" diesen Verhältnissen $z$. B. bei einer Klemmenspannung von $0,05 \mathrm{~V}$ ein dauernder Strom von $0,25 \cdot 10^{-4} \mathrm{Amp}$, bei $0,128 \mathrm{~V}$ von $1,0 \cdot 10^{-1}$ Amp. bei Elektrodenflächen von $1,5 \mathrm{qcm}$ das Wasser zersetzen, und durch die Elektrolytprodukte einerseits Hydrochinon oxydieren, andererseits Chinon reduzieren. Nach dem oben Gesagten hängt die erreichbare Stromstärke von der Geschwindigkeit dieser Reaktionen $\mathrm{ab}$, denn jedes von den Depolarisatoren verbrauchte $\mathrm{O}$ -

1) F. Foerster, Elektrochemie der wässerigen Lösungen, 2. Aufl. (Leipzig 1914), S. 295. Ich verweise überhaupt bezüglich der im folgenden herangezogenen Erscheinungen der "chemischen Depolarisation" und ihres Zusammenhangs mit der elektrolytischen Stromdichte auf die in diesem Buch gegebene Darstellung der Elektrolyse.

2) Vg1. F. Haber u. R. Ruß, Zeitschr. f. physik. Chem. 47, 257 (1904). 
resp. H-Atom wird durch erneute Elektrolyse ersetzt, und so entsteht fortwährend die Möglichkeit für den Eintritt neuer Elektrizitätsmengen. Depolarisieren wir mit rasch reagierenden Stoffen, z. B. mit Jod-JodkaliumLösung, so erhalten wir die Stromstärke von $0,25 \cdot 10^{-4}$ Amp. pro $1,5 \mathrm{qcm}$ bereits bei Anlegung einer Klemmenspannung von Bruchteilen eines Millivolts. Mit Rücksicht auf die folgenden Betrachtungen habe ich aber das langsamer reagierende Hydrochinon besonders erwähnt. Spannungen, geringer als sie im lebenden Organismus vorkommen, genügen also zur dauernden Unterhaltung der Elektrolyse; wenn nur durch geeignete chemische Reaktionen für unausgesetzte Depolarisation der Elektroden gesorgt ist.

Es fragt sich nun weiterhin, inwiefern die Beschaffenheit der Elektroden für diesen Vorgang in Frage kommt. Man könnte denken, daß diese unbedingt aus Metall sein müssen, das doch durch sein großes Aufnahmevermögen für Elektronen zur Ladung und Entladung von Ionen besonders geeignet ist. In kapillaren Systemen kann aber elektrolytische Zersetzung auch ohne metallische Elektroden erfolgen, durch einen Vorgang, der von $\mathrm{Braun}^{1}$ ) beschrieben und als Stenolyse bezeichnet worden ist. Schickt man nämlich durch ein Diaphragma aus Ton oder von Sprüngen durchsetztem Glas, das z. B. beiderseits an $\mathrm{AgNO}_{3}$-Lösung grenzt, einen elektrischen Strom, so erfolgt Elektrolyse, und zwar wird an der der Anode zugewandten kapillaren Seite Silber ausgeschieden, während an der entgegengesetzten Silbersuperoxyd entsteht. Diese Silbersuperoxydbildung ist der Typus einer depolarisierenden elektrolytischen Oxydation, und erfolgt ebenso auch an metallischen Anoden. Eine Erscheinung, die offenbar auf derselben Grundlage beruht, hatte bereits früher Ostwald ) beschrieben. Er erzeugte in einer Gelatineschicht eine Ferrozyankupfermembran, indem er die Schicht einerseits mit Kupfersulfat, andererseits mit Ferrozyankalium in Berührung brachte. Schickte er dann einen Strom durch die Membran, und zwar vom Kupfersulfat nach dem Ferrozyankalium, so schied sich an ihrer anodischen Seite metallisches Kupfer ab. Aehnliche Erscheinungen an verschiedenen Membranen haben später $\mathrm{Tamman} \mathrm{m}^{3}$ ) und $\mathrm{Bethe}$ und Toropof $\mathrm{f}^{4}$ ) beschrieben.

I) W. B r a u n, Ann. d. Phys. 42, 450 ff. (1891) und 44, 473 ff. (1891).

2) W. Ostwa1d, Zeitschr. f. physik. Chem. 6, 71 (1890). S. 1.12

3) G. T a m m a n n, Nachr. d. Ges. d. Wiss. Göttingen math.-phys. Kl. 1891,

4) A. Bethe u. A. Toropoff, Zeitschr. f. physik. Chem. 88, 731 (1914), 
Unter allen Umständen ist der Eintritt der Elektrolyse am Diaphragma ein Zeichen dafür, daß dieses durch den Strom polarisiert wird, d. h. dab zwischen seinen beiden Flächen eine Spannungsdifferenz entsteht, die hinreicht, um die betreffende chemische Reaktion $z u$ erzwingen. Im einzelnen hat $\operatorname{Coeh}^{1}$ ) eine theoretische Deutung des Phänomens ergeben. Er geht dabei von seiner durch das Studium elektrischer Grenzflächenspannungen gewonnenen Anschauung aus, daß diese nicht allein auf ungleichmäßiger Ionenverteilung beruhen, sondern ursprünglich auf dielektrischen Verschiebungen, wobei z. B. in unserem Falle elektrisch geladene Wasser- und Membranteilchen auftreten würden. Diese Grundanschauungen von dielektrischen Verschiebungen an nichtmetallischen Grenzflächen hat Lenard ${ }^{2}$ ) auf experimenteller und theoretischer Basis eingehend entwickelt und dabei als Ladungsträger an der Flüssigkeitsoberfläche komplexe Moleküle, also Molekülaggregate, erkannt. Die Beachtung dieser Arbeiten ist für die Physiologie von großer Wichtigkeit, denn bisher herrscht hier die Anschauung vor, daß alle kapillarelektrischen Erscheinungen nur auf Ionenverschiebung zurückzuführen seien.

Coehn's Erklärung der Stenolyse geht nun von der Tatsache aus, da $\mathrm{B}$ in einer von elektrischem Strom durchflossenen Kapillare konvektive Flüssigkeitsbewegungen eintreten, eine Erscheinung, die man als Elektroosmose bezeichnet. Dabei treten seiner Anschauung gemäB an dem einen Ende der Kapillaren dauernd positiv geladene Wasserteilchen, die den elektrischen Strom transportieren, aus, während am entgegengesetzten Ende negativ geladene Wasserteilchen zur Entladung frei werden. Diese nunmehr räumlich getrennten, entgegengesetzten Ladungen bewirken, genau wie indifferente MetallelektrodenElektrolyse, in dem beschriebenen Beispiel Abscheidung von Silber und Silbersuperoxyd.

Durch diese Betrachtungsweise ist es Coehn möglich gewesen, das verschiedene Verhalten verschiedener Salzlösungen bei der Stenolyse zu erklären, vơn denen die einen, wie Gold- und Platinlösungen, ferner Silbernitrat, Cuprochlorür, Ferrosulfat Metallabscheidungen zeigen, die anderen wie Kuprisulfat, Ferrichlorid, Zinksulfat nicht. Coehn weist zunächst darauf hin, dab auch aus dem Kupfersulfat an der der Anode zugewandten, als Kathode wirkenden Kapillarenseite Kupfer-

1) A. Coehn, Zeitschr. f. physik. Chem. 25, 651 (1898).

2) P. Lenard, Probleme der komplexen Molekïle, SB. der Heidelberger Akad. d. Wiss. Abt. A (1914), Nr: 27-29. 
ausscheidung erfolgen wird; da aber an dem entgegengesetzten Ende resp. an dem als Mittelleiter wirkenden Metall die entsprechende Menge Sauerstoff und Schwefelsäure entstehen muß, wird diese das ausgeschiedene Metall immer wieder auflösen, und es kann so zu keinem Wachstum der Membran kommen. Letzteres erfolgt jedoch dann, wenn entweder die Säure das ausgeschiedene Metall nicht angreift, wie z. B. Gold oder Platin, oder wenn ein unlösliches Superoxyd entsteht, wie beim Silber, oder endlich, wenn die Lösung ein Ion enthält, daß durch Oxydation höhere Wertigkeit annimmt, wie z. B. Cuprooder Ferrolösung; mit einem Wort, die Stenolyse tritt dann ein, wenn die Wiederoxydation des ausgeschiedenen Metalls durch den anodischen Prozeß unterbleibt, entweder deswegen, weil dieses zu stark elektropositiv ist, oder, uni das ist der Fall der uns interessiert, wenn elektrolytische Oxydation an der der Kathode zugewandten, anodisch wirkenden Kapillarenseite erfolgt. $Z \mathbf{u}$ dieser Erklärung paßt es, daß in Ostwald's oben erwähntem Membranversuch auch aus Cuprisulfat Kupfer "ausgeschieden wird: Hier befand sich nämlich auf der Gegenseite die elektrolytisch oxydierbare Ferrozyankaliumlösung.

Ein Punkt ist aber noch zu beachten: wenn der Vorgang in der Kupfersulfatlösung so wie ihn Coehn schildert, dauernd verlaufen würde, so müßte Abscheidung von Wasserstoff und Sauerstoff in Bläschenform erfolgen; denn der Sauerstoff wird ja durch kein Reduktionsmittel beschlagnahmt, die Auflösung des Kupfers in der Säure muß aber $z u$ fortgesetzter.Wasserstoffbildung führen. N Nun war aber in keiner der angewandten Lösungen, auch in Alkalisalzlösungen und in Säuren, eine Blasenbildung $\mathrm{zu}$ konstatieren; das kann nur darin seinen Grund haben, daß die Potentialdifferenz zu beiden 'Seiten der polarisierten Membran nicht genügt, um die Elektrolyse des Wassers zu unterhalten; denn wenn einmal die Bedingungen für den Eintritt elektrolytischer Vorgänge gegeben sind, so ist die Frage, welche Ionen entladen werden, lediglich von dem wirksamen Potential abhängig; und so wird es verständlich, daß die dauernde Elektrolyse des Kupfersulfats möglich ist, wenn ein Depolarisator für dauernde Entfernung des Elektrolytsauerstoffs sorgt, während ohne dessen Anwesenheit die Elektrolyse zum Stillstand kommt.

Ich bin mir wohl bewußt, daß die Stenolyse in Anbetracht der physiologischen Wichtigkeit, die ihr meines Erachtens beizumessen ist, noch einer eingehenden experimentellen Untersuchung bedarf. Deren Weg ist durch das Gesagte vorgezeichnet: es sind die Beziehungen zwischen vier Gröben festzustellen: dem Elektrodenpotential, der 
Polarisationsspannung zu beiden Seiten der Membran, der Grenzspannung für den Eintritt der Stenolyse einer Lösung oder Lösungskombination, und endlich der Zersetzungsspannung dieser Lösung, resp. der algebraischen Summe der Potentiale beider Elektrodenvorgänge. Ich hoffe die Lücke bald ausfüllen zu können ${ }^{1}$ ); doch sind Braun's experimentelle Ergebnisse und Coehn's Theorie bereits jetzt geeignet, die Grundlage für die folgenden Betrachtungen abzugeben. Uebrigenș sind nicht einmal die Einzelheiten der Coehn'schen Theorie für uns von Bedeutung, sondern nur die Grundauffassung, daß die Stenolyse nicht einen Vorgang sui generis darstellt, sondern cinen echten elektrolytischen Prozeb, bei dem die Entladung der Ionen nach den allgemeingüitigen Gesetzen erfolgt.

In den beschriebenen Beispielen kommt die die Stenolyse erzeugende Membranspannung durch äußere Stromzuführung zustande; es kann aber auch in der Membran selbst der Sitz der treibenden elektrischen Kraft liegen. Glasdiaphragmen, in Säure oder Alkali getaucht, nehmen elektrische Ladungen an, deren Verhalten von Haber und Klemensiewic $z^{2}$ ) eingehend studiert wurde. Sie führen dies darauf zurück, daß die gequollene Grenzschicht des Glases sich verhält wie eine semipermeable Membran, die $\mathrm{H}^{\circ}$ - uud $\mathrm{OH}^{\prime}$-Ionen aufnimmt, nicht aber z. B. $\mathrm{Cl}^{\prime}$ und $\mathrm{K} \cdot$.' Das Bestreben, die entgegengesetzt geladenen Ionen auf diese Weise zu trennen, erzeugt eine Spannung des Glases gegen die Flüssigkeit. In der Säure lädt es sich positiv, im. Alkali negativ, und der Unterschied der Spannungen zwischen $\mathrm{n} / 1 \mathrm{HCl}$ und $\mathrm{n} / 1 \mathrm{KOH}$ beträgt im Maximum $0,81 \mathrm{~V}$. In einem solchen Falle würde nach dem für die Erscheinung geltendem Gesetz eine Aenderung der $\mathrm{H}^{\cdot}$ - resp. $\mathrm{OH}^{\prime}$-Konzentration um einc Zehnerpotenz eine Spannungsdifferenz von 0,058 Volt bewirken, so daß z. B. eine Glashaut, die einerseits an $\mathrm{n} / 1$, andererseits an $\mathrm{n} / 1000 \mathrm{HCl}$ grenzt, einen Abfall von 0,174 Volt aufweisen würde. Am größten wäre die Wirkung geringer stofflicher Aenderungen in der Nähe des Neutralitätspunktes der Lösungen: 0,0001 n alkalische Lösung würde gegen $0,0001 \mathrm{n}$ saure infolge des großen Unterschiedes im $\mathrm{H}^{\cdot}$-Ionengehalt eine Spannungsdifferenz von 0,348 Volt erzeugen.

Ist nun eine solche Glasmembran von Sprüngen durchsetzt, so wird die Spannungsdifferenz zur Erzeugung lokaler Membranströme

1) Bis jetzt ist mir das noch nicht möglich gewesen; die vorliegende Arbeit ist in langem Lazarettaufenthalt entstanden.

2) F. Haber u. Z. Klemensiewicz, Zeitschr. f. physik. Chem. 67385. (1909). 
führen ${ }^{1}$ ), wobei das Glas ebenso wie die Flüssigkeit, freilich in weit geringerem Grade, als elektrolytischer Leiter fungiert. An seinen beiden Grenzflächen herrschen die beschriebenen Spannungen; innerhalb der Kapillaren entsteht nun zwar infolge der ungleichen Wanderungsgeschwindigkeit der Ionen ein Flüssigkeitspotential, das der Grenzflächenspannung entgegenwirkt; es ist aber im Verhältnis 0,0357/0,058 kleiner, und so wird im beschriebenen Falle mit der Spannung von 0,2 Volt ein elektrischer Strom durch die Kapillare und in entgegengesetzter Richtung durch die Glassubstanz getrieben. Damit sind aber die. Bedingungen der Stenolyse gegeben, sofern nur, wie es oben geschildert wurde, die Möglichkeit für die Abscheidung der Elektrolysenprodukte besteht, oder aber für ihre dauernde Beschlagnahme durch geeignete Depolarisatoren.

Nunmehr sind wir aber bei den Verhältnissen angelangt, wie sie im lebenden Protoplasma herrschen. Ebenso wie Glasoberflächen, sind plasmatische Grenzschichten in Berührung mit Elektrolytlösungen der Sitz von Spannungen, die, worauf Ostwald zuerst aufmerksam gemacht hat, auf ungleiche Ionenverteilung zurückgeführt werden können. Mögen über die Einzelheiten dieses Phänomens noch Meinungsverschiedenheiten bestehen, so lassen sich doch alle abweichenden Anschauungen auf die allgemeine Formel Bernstein's ${ }^{2}$ ) bringen, daß die Spannungen an Membranen auftreten, die „für die Anionen und Kationen der Elektrolyse im Innern der Zellen oder in der AuBenflüssigkeit verschiedene Permeabilität oder verschiedenes Adsorptionsbzw. Lösungsvermögen besitzen.

Die hier genannten drei Eigenschaften sind voneinander nicht unabhängig ; die Permeabilität hängt nach der von den einen ( $z$. B. Nernst) vertretenen Auffassung vom Lösungsvermögen $a b$, während andere (Traube) sie mit der Oberflächenaktivität in Zusammenhang bringen. Welche von diesen Eigenschaften dafür und für die bioelektrischen Potentiale ausschlaggebend ist, ist für uns nebensächlich. Das Wesentliche ist die ,Reversibilität“ der Membransubstanz für gewisse Kationen, ihre Eigenschaft sich in umkehrbarer Weise ausschließlich mit ihnen oder doch wenigstens in wesentlich höherem Grade als mit den dazu gehörigen Anionen zu beladen.

1) Vgl, darüber die Arbeit von H. Freundlich, Koll.-Zeitschr. 18, 11 ff. (1916), auf die wir noch ausfibrlicher zu sprechen kommen.

2) J. Bernstein, Elektrobiologie (Braunschweig 1912), S. 198. 
Das geht mit hervorragender Klarheit aus den Untersuchungen hervor, die Loeb und $\mathrm{Beutner}$ ) an Pflanzen- und Tierorganen ausführten und deren Ergebnisse sich mit großer Treue qualitativ und quantitativ an lipoïden Grenzflächen reproduzieren ließen. In Berührung mit Saizlösungen nehmen dabei die Membranen umso positivere Spannung, die berührenden Flüssigkeiten umso negativere an, je höher die Konzentration ist; und die so erzeugten Spannungsdifferenzen erreichen in manchen Fällen fast die aus der Nernst'schen Formel zu berechnende Größe von 0,058 Volt für die Aenderung um eine Zehnerpotenz. Z. B. betrug der Unterschied der durch $1 / 10 \mathrm{n}$ und $1 / 1000 \mathrm{n} \mathrm{NaCl}$-Lösung erzeugten Potentiale bereits $0,1 \mathrm{~V}$; $z$ wischen $1 / 8 \mathrm{n} \mathrm{Na} J$ und $1 / 1000 \mathrm{n} \mathrm{NaJ}$ $0,125 \mathrm{~V}$. Besonderes Interesse beanspruchen für unsere folgenden Betrachtungen die Versuche ïber die Wirkung von $\mathrm{H}^{-}$-lon. Auf den ersten Blick will es scheinen, als ob in dieser Hinsicht eine gewisse Unklarheit der Versuchsergebnisse herrschte; doch bei näherer Analyse ergibt sich, daß gerade sie den Forderungen der Theorie besonders gut entsprechen, und einen Anknüpfungspunkt für weitere Erforschung des Gegenstandes bilden.

Aus der zweiten der genannten Publikationen (S. 306) ergibt sich, daß das $\mathrm{H}^{-}$-Ion in gleicher Richtung wirkt, wie andere Kationen, nur bei gleicher Konzentration stärker: eine $\mathrm{HCl}$-Lösung wirkt etwa so, wie eine $10 \mathrm{mal}$ so konzentrierte $\mathrm{KCl}$-Lösung. Mit steigender Säurekonzentration wird auch hier die Membran positiver, und die Versuche mit isohydrischen Lösungen verschiedener Säuren zeigen, daß die Natur des Anions keinen wesentlichen Einfluß auf den Ausschlag hat. Nichtsdestoweniger hatten die Autoren in der ersten Arbeit Versuche mitgeteilt, in denen die Aenderungen der $\mathrm{H}^{-}$-Ionenkonzentrationen ohne Einflub waren; die durch $\mathrm{n} 20 \mathrm{NaCl}$-Lösung erzeugte Spannung blieb unverändert, gleich viel, ob die Lösung neutral, durch $1 / 1000 \mathrm{Na} \mathrm{OH}$ alkalisch oder durch $1 / 1000 \mathrm{HCl}$ sauer war. Aus diesen Versuchen schlossen die Verfasser die Plasmahaut sei nicht reversibel für das $\mathrm{H} \cdot$-lon. Sie bezeichneten dieses Ergebnis als unerwartet; man muß aber weitergehen: wäre ihre Schluffolgerung berechtigt, so würde sie die ganze, von den Verfassern entwickelte Theorie umstürzen; denn es ist ganz ausgeschlossen, daß an einer Membran, die sich durch vorhandene Aufnahmefähigkeit von $\mathrm{K}$ und fehlende von $\mathrm{Cl}^{\prime}$ elektrisch belädt, $\mathrm{HCl}$ elektromotorisch unwirksam wäre. Das würde die ganz

1) J. Loeb u. R. Be ut ne r, Biochem. Zeitschr. 41, 1 (1912); 44, 303 (1912); 51, 288 (1913); 59, 159 (1914). 
undenkbare Annahme voraussetzen, die wasserdurchtränkte Membran sei nicht aufnahmefähig für $\mathrm{OH}^{\prime}$. Die Dinge liegen aber anders. Berührt eine Lösung von $\mathrm{n} / \mathrm{i} 0 \mathrm{~K} \mathrm{Cl}$ und $\mathrm{n} / 1000 \mathrm{HCl}$ die Membran, so wirken auf sie gleichzeitig zwei elektromotorische Kräfte, eine, $\varepsilon_{\nwarrow}$, durch die Verteilung von $\mathrm{K}$-Ionen, und die andere, $\varepsilon_{\mathrm{H}}$, durch die Verteilung von $\mathrm{H}$-Ionen bedingt. Diese Spannungen werden sich aber ebensowenig summieren, wie ctwa zwei gleichzeitig an einer unangreifbaren Elektrode tätige Oxydationspotentiale. Es wird nicht einmal das Stärkere in diesem Falle, $\varepsilon_{K}$, rein zur Ausildung gelangen; da nämlich durch seine Wirkung die durch die Verteilung der $\mathrm{H}$-Ionen hervorgerufene Spannung überschritten ist, werden diese nunmehr aus der Membran herausgezogen werden, indem sich durch ihre Verteilung das Bestreben zur Wiederherstellung des für sie geltenden Spannungsgleichgewichts geltend macht. Bei welcher Spannung nun der Endzustand liegt, hängt von dem Geschwindigkeitsverhältnis ab, mit dem die nunmehr entgegengesetzten Einflüsse der $\mathrm{K} \cdot$ und $\mathrm{H}^{-}$-Ionen wirken. Im vorliegenden Fall werden die $\mathrm{K}$-Ionen infolge ihrer viel größeren Konzentration vorherrschen und die verdünnte Säurelösung muß daher ohne merklichen Einfluß bleiben. Dem entspricht es auch, daß Loeb und Beutner einen immer stärkeren Einfluß von Säure und Alkali fanden, je verdünnter die $\mathrm{NaCl}$-Lösung war, zu der die betreffenden Zusätze gemacht wurden; wenn sie von $\mathrm{n} / 500 \mathrm{NaCl}$ - Lösung ausgingen, so bewirkte ein Säurezustand von $\mathrm{n} / 1000 \mathrm{NaCl}$ einen Effekt von $0,027 \mathrm{~V}$. in dem gleichen Sinn wie eine Erhöhung der Salzkonzentration. Ebenfalls waren, wie von den Verfassern kurz bemerkt wird, Alkalizusätze wirksam, natürlich in entgegengesetztem Sinne.

Diese Ergebnisse entsprechen also vollkommen der Theorie und sie müssen in gleicher Weise zustandekommen, wenn nicht $\mathrm{K}$ mit $\mathrm{H}$-Ionen zusammenwirken, sondern auch bei jeder beliebigen anderen Kationenkombination; das durch Konzentration und Reaktionsgeschiwindigkeit stärker wirksame Ion wird stets das schwächer wirkende unterdrücken. Hieraus ergibt sich die Aufgabe, die Wirkung von Elektrolytkombinationen auf geeignete lebende und tote Membranen zu studieren. $\mathrm{Ob}$ dies zu Anhaltspunkten für die Erklärung der bekannten Einflüsse reiner und gemischter Elektrolytlösungen, sowie für die Lähmung von Muskeln durch elektromotorisch wirksame Salze führen wird, ist abzuwarten.

Unter den beschriebenen Verhältnissen ist es nicht weiter verwunderlich, daß sich in Lo eb und Beut n er's Versuchen der salzreiche Preßsaft des Apfels trotz seiner sauren Reaktion nicht wie eine Säurelösung, sondern wie eine $\mathrm{KCl}$-Lösung gleicher Leitfähigkeit verhielt. 
Die vorherrschenden $\mathrm{K} \cdot$ Ionen unterdrücken eben die $\mathrm{H} \cdot$-Wirkung. Für uns aber bietet die starke elektromotorische Wirksamkeit dieses Saftes bedeutendes Interesse. Lehrt sie uns doch, daß im normalen Zustand der Pflanzenzelle zwischen der Vakuolenhaut, die mit diesem konzentrierten, Zellsaft in Berührung steht, und der äußeren Plasmamembran eine Spannungsdifferenz herrschen muß, die nach Loeb and Beutner's Ergebnissen auf mehr als $0,1 \mathrm{~V}$. zu veranschlagen ist. Ueberall aber, wo in der Zelle Konzentrationsverschiedenheiten auftreten, werden in gleicher Weise die Bedingungen für die Erzeugung ähnlicher Spannungen vorhanden sein, und je geringer an irgend einem Ort die Salzkonzentration ist, um so mehr wird sich der Einfluß der durch den Stoffwechsel so leicht veränderlichen $\mathrm{H}$-lonenkonzentration geltend machen.

Nun aber haben wir noch eine zweite prinzipielle Feststellung zu machen; daß nämlich nicht nur für das Auftreten von Spannungen, sondern auch für die Ausbildung lokaler Membranströme die physikalischen Bedingungen gegeben sind. Solche Ströme werden sich nach Freundlich's Ausführungen einstellen, wenn in einem Kapillarensystem der Spannungsausgleich einerseits durch die Kapillaren, andererseits durch die festen Membranteilchen möglich ist. Wie weit nun im Einzelnen die Ansichten über den Bau der plasmatischen Membran auseinandergehen, so kann doch über ihre kapillare Struktur kein Zweifel herrschen. Betrachtet doch die physikalische Chemie jedes Gel als ein Kapillarsystem; und bei der Plasmahaut werden die Verhältnisse noch dadurch in gleicher Richtung kompliziert, daß sie wahrscheinlich aus Bausteinen verschiedener Natur, Lipoïden und Proteïden, besteht. Dadurch ist aber von vornherein die Bedingung gegeben, dab ein und dieselbe berührende Lösung an verschiedenen Punkten verschiedene Spannungen erzeugt, und das muB notwendigerweise zur Bildung von Stromkreisen führen, die sich einerseits durch die elektrolytisch leitende Wandsubstanz, andererseits durch die lösungserfüllten Kapillaren bewegen. Es werden sich also hier dieselben Verhältnisse einstellen, wie wir sie oben an den Glasdiaphragmen beschrieben haben. Diese Lokalströme müssen aber stenolytische Zersetzung des Wassers hervorrufen und dauernd erhalten, sobald die Bedingungen für fortgesetzte Depolarisation in der Weise gegeben sind, wie es oben im AnschluB an Coehn's Theorie dargestellt wurde. $\mathrm{Ob}$ das im Protoplasma der Fall ist, haben wir nunmehr zu untersuchen.

Zur Beantwortung dieser Frage müssen wir uns zunächst über das Maß der Leistung klar werden, das von diesem Vorgang zu erwarten ist. Im Maximum bestände es in der Verbrennung des gesamten, 
in der Atmung verbrauchten Materials durch elektrolytisch erzeugten Sauerstoff, im früher zitierten Beispiele der lebenden Katzenleber, eines sehr tätigen Organs, also $3 \mathrm{mg}$ pro $1 \mathrm{~g}$ Plasma in der Stunde. Da nun jedes Teilchen der lebendigen Substanz an der Atmung Anteil haben mub, so würde sich diese Reaktion nach der oben ausgeführten Berechnung auf eine Fläche von etwa $6-60 \mathrm{qm}$ verteilen. Nun ist aber das elektrochemische Aequivalent für einen Sauerstoffverbrauch von $3 \mathrm{mg}$ pro Stunde $=10 \cdot 10^{-3}$ Amp. Diese Stromstärke auf $6 \mathrm{qm}$ verteilt ergibt eine Stromdichte von nur 1,7 $10^{-7}$ Amp. pro $\mathrm{qcm}$, bei $60 \mathrm{qm}$ Fläche würde sie sogar nur 1,7 $10^{-8}$ Amp. betragen. Ein Strom von so minimaler Größenordnung wäre mittels Depolarisation durch das Atmungsmaterial z. B. den Traubenzucker und seine Abbauprodukte, sowie durch den atmosphärischen Sauerstoff und die vorhandenen Sauerstoffüberträger aufrecht $z \mathfrak{u}$ erhalten.

Betrachten wir beide Elektrodenvorgänge gesondert und fassen wir zunächst das Schicksal des naszierenden Wasserstoffes ins Auge. Daß dieser ïberall wo er auftritt der Oxydation unterliegen muß, kann keinem Zweifel unterliegen. Es vermag nämlich schon gelöster atmosphärischer Sauer̦stoff den an der Kathode frei werdenden Wasserstoff $z u$ oxydieren und zwar zu Wasserstoffsuperoxyd ${ }^{1}$ ). Wo dieses aber mit der allenthalben vorhandenen Katalase zusammentrifft, muß es zersetzt werden, wobei der entstehende Sauerstoff natürlich noch energischer auf naszierenden. Wasserstoff wirkt. Mit dieser Funktion, die wir der Katalase zuschreiben, stimmt die Tatsache überein, daß der Gehalt verschiedener Organe an diesem Enzym itm allgemeinen mit ihrem Oxydationsvermögen parallel geht ${ }^{2}$ ).

Außerdem aber ist noch die Wirkung der verschiedenen Sauerstoffüberträger in Rechnung zu ziehen. Mit der Tatsache, daß Wasserstoffakzeptoren in der Zelle vorhanden sind, hat ja unter anderen auch Palladin gerechnet, und darin die Funktion der sogen. „Atmungschromogene" der Pflanzenzelle erblickt, Verbindungen verschiedener Natur, die z. T. dem Brenzkatechin verwandt sind. Es kommen aber meines Erachtens in dieser Hinsicht auch die komplizierten Systeme jener oxydierender Fermente in Frage, die zum Teil durch physiologisch ganz unverständliche Reaktionen charakterisiert sind, höchstwahrscheinlich aber alle mit naszierendem Wasserstoff reagieren werden;

1) F. Foerster, Elektrochemie usw. S. 296.

2) T. Thunberg, Skandin. Arch. f. Physiol. 35 (1915); vgl, auch Burge, Amer. Journ. Physiol. 47 u. 48, Journ. Biochem. 37, Ref. i. Chem. Ztbl. 1919 [III], S. 28 t. 135. 
dieser wäre dann als das eigentliche Substrat ihrer Oxydationsfähigkeit zu betrachten. In diesem Punkt ist eine weitere Möglichkeit gegeben, die Forderungen der elektrolytischen Atmungstheorie einer experimentellen Prüfung zu unterwerfen, denn das Reaktionsvermögen der genannten Enzyme mit naszierendem Wasserstoff, also ihre Fähigkeit zur kathodischen Depolarisation, ist einer exakten Messung zugänglich. Es kommt nun noch hinzu, daß das überall verbreitete $\mathrm{Fe}^{*}$-Ion in diesen Vorgang eingreifen wird, denn nichts ist zur Beschleunigung von Depolarisationsvorgängen geeigneter als Metall-Ionen, die verschiedene Wertigkeitsstufen annehmen können. Man hat ja auch stets die Bedeutung des Eisens auf dem Gebiet der Oxydationsvorgänge gesucht, aber erst neuerdings hat $\mathrm{War} \mathrm{bur}^{\mathrm{l}}$ ) einen instruktiven Beweis dafür geliefert. Er fand, daß die aus zusammengeflossenen Seeigeleiern gebildete, noch lebhaft atmende Flüssigkeit zirka $0,02 \mathrm{mg} F \mathrm{Fe}$ pro $100 \mathrm{mg} \mathrm{N}$ enthielt. Setzte er nun die gleiche Fe-Menge noch hinzu, so wurde die Atmung der Flüssigkeit um ca. 75 Prozent gesteigert, während größere Zusätze unwirksam blieben, sodaß dadurch gerade die Bedeutung der minimalen Fe-Mengen des Plasmas in helles Licht tritt.

Kann es also keinem Zweifel unterliegen, dab die geringen Konzentrationen von Wasserstoff, die die Lokalströme des Plasmas begleiten müssen, einer glatten Oxydation unterliegen, so haben wir nunmehr noch die Frage nach dem Schicksal des naszierenden Sauerstoff zu erörtern. Seine Entfernung, also die anodische Depolarisation, muf durch organische Substanzen erfolgen; käme Hydrochinon in Frage, so würde eine Spannung von $0,128 \mathrm{~V}$, wie wir sie z. B. an Salz- und Verletzungsströmen von Pflanzenteilen oft beobachten, eine Stromstärke von $1 \cdot 10^{-1}$ Amp. pro $1,5 \mathrm{qcm}$ unterhalten. Zur Depolarisation der Zellströme unter den geschilderten Bedingungen, würde es also nach

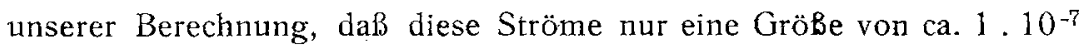
Amp. pro qcm haben müssen, genügen, wenn die organischen Substanzen mit einer Geschwindigkeit oxydiert würden, die etwa 500 bis 5000 mal kleiner ist, als die Reaktionsgeschwindigkeit des Chinhydrons; und selbst dieses ist doch in den zu den zitierten Messungen angewendeten sauren Lösungen ein recht stabiler Körper.

Betrachten wir im Einzelnen die für die Sauerstoffdepolarisation in Frage kommenden organischen Stoffe, so ist in erster Linie der Traubenzucker zu erwähnen. Ist er an sich zu träge, um mit atmosphärischem Sauerstoff zu reagieren, so wird er doch bereits durch

1) O. Warburg, Zeitschr. f. physiol. Chem. 92, 231 (1914). 
die denkbar gelindesten Oxydationsmittel z. B. $\mathrm{H}_{2} \mathrm{O}_{2}+\mathrm{Fe}$ angegriffen. Das erinnert uns wiederum an die Anwesenheit des Fe-Ions im Organismus, das ebenso wie bei der kathodischen auch bei der anodischen Depolarisation eine entscheidende Rolle spielen muß. So ist garnicht zu bezweifeln, daß auch der Traubenzucker selbst der Oxydation durch naszierenden Sauerstoff im Protoplasma anheimfallen muß. Umsomehr wird das aber mit seinen noch leichter angreifbaren Spaltungsprodukten sein ${ }^{1}$ ), deren Bildung höchstwahrscheinlich die erste Stufe beim oxydativen Abbau des Zuckers bildet. Die Oxysäuren sind, ebenso wie übrigens auch die Aminosäuren, wirksame Depolarisatoren bei der gewöhnlichen Elektrolyse und sie werden dabei in den folgenden Reaktionsgleichungen entsprechend zerlegt: ${ }^{2}$ )

$$
\text { R. } \mathrm{CH}_{2} \cdot \mathrm{OHCOOH}+\mathrm{O}=\mathrm{R} \mathrm{COH}+\mathrm{CO}_{2}+\mathrm{H}_{2} \mathrm{O}
$$

$\mathrm{COOH}\left(\mathrm{CH}_{2} \mathrm{OH}\right)_{n} \mathrm{COOH}+2 \mathrm{O}=\mathrm{COH}\left(\mathrm{CH}_{2} \mathrm{OH}\right)_{\mathrm{n}-2} \mathrm{COH}+2 \mathrm{CO}_{2}+2 \mathrm{H}$

$\mathrm{RNH} \mathrm{NH} \mathrm{H}_{2} \cdot \mathrm{COOH}+\mathrm{O}=\mathrm{RCOH}+\mathrm{CO}_{2}+\mathrm{NH}_{3}$

In all diesen Gleichungen erkennen wir Reaktionen wieder, die auch für den Organismus von Bedeutung sind. Es ist natürlich nicht gesagt, $\mathrm{da} B$ unter den hier herrschenden Bedingungen, vor allem bei der geringen Sauerstoffspannung, unter der die stenolytischen Oxydationsprozesse im Protoplasma erfolgen müssen, die Reaktionen in der gleichen Weise vor sich gehen. Ich halte es nicht für unwahrscheinlich, daß hier znnächst in all diesen Fällen nur die Bildung der entsprechenden Ketosäure erfolgt, die dann weiter durch Karboxylasespaltung das gleiche Aldehyd liefern würde, das bei energischer elektrolytischer Oxydation von vornherein entsteht.

Ueberall aber würde es dabei zur Bildung von Aldehyden kommen, und es kann auch keinem Zweifel unterliegen, daß diese Körper im oxydativen Abbaustoffwechsel eine ebenso große Rolle spielen, wie in der Gärung. Ihre Weiterverarbeitung wird zu den entsprechenden Säuren führen; dabei ist aber zu beachten, daß an und für sich die $\mathrm{COH}-\mathrm{Gruppe}$ elektrolytisch gar nicht so leicht oxydierbar ist, sodaß man z. B. die elektrolytische Oxydation von Aethyl- und Methyl-Alkohol auf der Aldehydstufe zum Stehen bringen kann. Da ist nun das allgemeine Vorkommen der bereits eingangs erwähnten Aldehydfermente von großer Bedeutung; da sie Aldehyde mit jeder Art von Sauerstoff, also auch mit atmosphärischem, oxydieren, müssen sie um so leichter

1) Als erstes kommt jedenfalls Methylglyoxal in Frage. Vg1. C. Neuberg u. E. Re infurth, Ber. d. Deutsch. chem. Ges. 52, 1677 (1919).

2) C. Neuberg, Biochem. Zeitschr. 7, 527 (1908); F. Förster, Elektrochemie usw. S. $776 \mathrm{f}$. 
zur Uebertragung von Elektrolytsauerstoff befähigt sein. Auch in dieser Hinsicht werden Depolarisationsversuche interessante Aufschlüsse über die mit Hilfe dieses Ferments erreichbaren Stromdichten ergeben. Im Großen und Ganzen führen uns unsere Betrachtungen zu dem Ergebnis, daß für die anodische Depolarisation in dem minimalen Umfange, der für die elektrolytischen Erscheinungen im Protoplasma überhaupt in Betracht kommen kann, die Bedingungen jederzeit gegeben sind, sodaß überall, wo unter den geschilderten Voraussetzungen lokale Membranströme zustande kommen, sie auch zu einer dauernd unterhaltenen Stenolyse führen müssen; und so wird naszierender Wasserstoff und Sauerstoff überall entstehen und überall entfernt werden, wo sich im Protoplasma elektrische Potentialdifferenzen ausgleichen.

Träten diese regellos und zufällig auf, so würde das auch für die durch sie bewirkten stenolytischen Oxydationsprozesse gelten; das trifft aber nicht zu. Die Verteilung der Spannungen im Organismus ist streng gesetzmäßig; das beweist schon die Möglichkeit des Bestehens einer Elektrophysiologie, einer Lehre von der Verteilung der Spannungen an der Oberfläche der Organe und von der Aenderung, die diese Verteilung während ihrer Funktion erfährt. Wir wissen, daß an der intakten Pflanze im normalen Zustand völlig regelmäßige Potentialdifferenzen bestehen; daß bei Verletzungen zwischen den künstlichen Oberflächen, die bekanntlich sofort zum Sitz erhöhter Tätigkeit werden, und den intakten Teilen starke Ströme auftreten; und daß schließlich am Tier- und Pflanzenkörper jede physiologische Aktion, sei sie sensorisch, motorisch oder sekretorisch, mit einer Aenderung der elektrischen Spannungsverteilung verknüpft ist; das besagt aber nach den obigen Darlegungen, daß sie alle auch von einer gesetzmäßigen Aenderung der physiologischen Oxydation begleitet werden.

In diesem Punkte begegnen sich die Forderungen der Theorie mit der experimentellen Erfahrung; bekanntlich ist die Muskelkontraktion nicht nur von elektrischen Phänomenen begleitet, sondern auch von einer wesentlichen Steigerung des oxydativen Stoffwechsels; und das Gleiche ist bei verletzten Pflanzenteilen der Fall, bei denen die gesteigerte Wärmebildung und das Auftreten starker Verletzungsströme Hand in Hand gehen. Aus dem Gesagten können wir zunächst die unmitteibare Schlußfolgerung ziehen, daß zum Mindesten ein Teil der beobachteten Oxydationssteigerung in dem geschilderten Kausalzusammenhang mit den elektrischen Erscheinungen stehen; und damit würde sịch eine Präzisierung des bereits von Fick eingenommenen Standpunktes ergeben, daß bei der Muskelkontraktion primär Milchsäure 
durch Spaltung entsteht, sowohl die negative Schwankung, als auch die Kontraktion bewirkt und dabei der oxydativen Zerstörung anheimfällt. Der ursächliche Zusammenhang zwischen Milchsäurebildung, negativer Schwankung und Milchsäurezerstörung würde sich aus dem Gesagten ergeben.

Nun können wir der Natur der Dinge nach die elektrische Spannungsverteilung nur an den Organoberflächen beobachten, an den natürlichen oder den künstlich hergestellten. Es wird aber wohl niemand bezweifeln, daß Aktionsströme ebensogut auch zwischen den Teilen der Kernfigur zirkulieren oder zwischen ruhenden und bewegten Partien eines strömenden Protoplasten; mit einem Wort, daß sie auf den Grenzflächen im Innern des Protoplasmas ebensogut auftreten, wie auf dessen äukerer Membran $\left.{ }^{1}\right)$. So muß denn dauernd ein Netz von Strömen das lebenstätige Protoplasma durchziehen, begleitet von elektrolytischer Oxydation und Reduktion; und nun brauchen wir nur noch einen Schritt weiter zu gehen, um eine Antwort auf die Frage zu erhalten, von der wir ausgegangen sind: nach der Struktureigentümlichkeit des lebenden Protoplasmas, die imstande ist, gleichzeitig fördernd auf die physiologische Oxydation zu wirken und eine vielseitige Transformation der dabei freiwerdenden Energie zu ermöglichen. Die Annahme ist nicht mehr gewagt, daß in den kapillarelektrischen Erscheinungen des Protoplasmas der gesuchte Faktor liegt. Trifft das zu, so muB in den Zellen die Ausbildung der Spannungen so geregelt sein, daß die gesamte physiologische Verbrennung auf dem Wege elektrolytischer Oxydation vor sich geht. Daß hierfür die allgemeinen Grundbedingungen erfüllt sind, haben wir durch Berücksichtigung der dafür erforderlichen Stromdichten erkannt; es fragt sich nur, was für besondere Einrichtungen nötig wären, um die Verteilung des elektrolytisch betriebenen Atmungsprozesses auf die gesamte Oberfläche der plasmatischen Strukturen zu ermöglichen.

Zunächst ist es klar, daß für die Entstehung der Atmungsströme die $\mathrm{H} \cdot$ - Ionen der bei dem oxydativen Abbau des Zuckers intermediär entstehenden Säuren verantwortlich zu machen wären, wie es schon $\mathrm{Haber}$ im Anschluß an seine Glasversuche ausgesprochen hat. Wenn wir damit den Stoffwechselprozessen fundamentale Bedeutung als Ursache der bioelektrischen Erscheinung zuschreiben, so befinden wir uns keineswegs im Widerspruch mit der Membrantheorie, die zunächst als einfachste Erklärung für Potentialschwankungen Aenderungen der Perme-

1) Vgl. die Ausführungen von W. Pf effer, Pflanzenphysiologie II, 2. Auf1. (1904), S. 862. 
abilität herangezogen hat. Daß z. B. für die am Apfel beobachteten Verletzungsströme eine solche Erklärung unmöglich ist, hat sich in Loeb und Beutner's Versuchen deutlich gezeigt: Konzentrationsänderungen durch das Austreten des Zellsafts an den verletzten Stellen könnten den Effekt nur erklären, wenn dessen Konzentration mehr als grammmolar inbezug auf die wirksamen Ionen wäre. Loeb und Beutner ziehen denn auch Stoffwechselvorgänge zur Deutung des Phänomens heran; das stimmt mit den älteren Erfahrungen Haackes ${ }^{1}$ ) über Pflanzenströme überein, der z. B. beobachtete, daß lokale Sauerstoffentziehung, also plötzliche Aenderung des Atmungsstoffwechsels, heftige elektrische Reaktionen hervorrief.

Die Bedingungen für die gleichmäßig verteilte Stromerzeugung durch die in der Atmung entstehenden Säuren wären dann am einfachsten erfüllt, wenn an jeder Doppelfläche eines Strukturelements der gesamte Zuckerabbau auf der einen Seite, der Eingriff des atmosphärischen Sauerstoffs auf der anderen Seite sich abspielte. An der einen, der Säureoberfläche, würden sich die Metmbranteilchen positiv, die Flüssigkeit negativ laden; nach dieser Seite hin würde sich also der positive Strom durch die Kapillaren bewegen, an deren Mündung negativ geladene $\mathrm{OH}$-Ionen unter Sauerstoffbildung entladen und die Abbauprodukte des Zuckers verbrennen. An der entgegengesetzten Seite würden aber die Oxydasen dauernd die Beseitigung des Elektrolytwasserstoffs bewirken. Am einfachsten kämen solche Doppelschichtèn zustande wenn - - und das ist ja eine aus mannigfachen Gründen naheliegende Vorstellung — alle Plasmateilchen polar gebaut und an den entgegengesetzten Enden mit verschiedenen Enzymen ausgestattet wären, so daß nur auf der einen Seite die die Zuckerverbrennung ein* leitende Spaltung vor sich geht.

Diese Anschaungsweise muß, wenn sie allgemeine Bedeutung beansprucht, auch auf anoxybiotische Vorgänge, auf intramolekulare Atmung und Gärung anwendbar sein. Tatsächlich ist ja der Eintritt der Elektrolyse nicht an den Sauerstoff gebunden, denn sie kann ohne weiteres durch die im ersten Akt des Gärungsprozesses aus dem Zucker entstehende Brenztraubensäure, Glyzerinsäure oder Milchsäure bewirkt werden. Die Entfernung des Sauerstoffs durch die Oxydation der Spaltungsprodukte würde in gleicher Weise vor sich gehen, wie bei der aëroben Atmung, nur für die Beseitigung des Elektrolytwasserstoffs

1) E. Haacke, Flora 1892, S $455 \mathrm{ff}$. 
steht kein atmosphärischer $O$ zur Verfügung und hierin muß die Besonderheit der anoxybiotischen Prozesse liegen.

Nun haben die Untersuchungen N e u b e r g's und seiner Mitarbeiter ${ }^{1}$ ) gelehrt, welche bedeutende Rolle in der alkoholischen Gärung die Aldehyde spielen, indem vor allem durch ein zum Zymasekomplex gehöriges Enzym, die Karboxylase, aus verschiedenen Substanzen, die als Zwischenprodukte der alkoholischen Gärung in Betracht kommen, Azetaldehyd abspaltet. Dieser muB, um zu Alkohol reduziert zu werden, mit einem anderen Aldehyd - dabei käme Methylglyoxal in Frage in Cannizzaro'sche Umwandlung treten; eine gekoppelte Oxydation und Reduktions-Reaktion bildet also einen Bestandteil des Gärungsprozesses. Diese Koppelung kann nun elektrochemisch erfolgen, indem die Oxydation durch den Elektrolytsauerstoff, die Reduktion durch den Wasserstoff bewirkt wird. Das Aldehydmolekül, das diesem letzteren ProzeB unterworfen ist, verträte in diesem Fall den atmosphärischen Sauerstoff, und hierin wäre sowohl der Unterschied, als auch die Analogie zwischen aerober und anaerober Atmung gegeben. Nötig ist hierzu auch wieder eine geeignete Verteilung der Glieder des Enzymkomplexes auf die beiden Membranseiten, und hierdurch wäre die Bedingung der Bindung der Enzyme an die Struktur erfüllt, die Rubner für die alkoholische Gärung fordert.

Derartige gekoppelten Reaktionen sind zweifellos bei allen Gärungsvorgängen vorhanden. Sie brauchen aber nicht unbedingt immer nach dem Muster der Canizzaro'schen Umwandlung zu erfolgen ${ }^{2}$ ). Z. B. ist dies bei der Buttersäuregärung nicht der Fall; diese verläuft offenbar so, daß Milchsäure in Azetaldehyd und Ameisensäure, diese letztere in Kohlensäure und Wasserstoff zerfällt. Der Azetaldehyd bildet durch Kondensation je zweier Moleküle $\left.\mathrm{Aldol}^{3}\right)$ ( $\beta$-Oxybuttersäurealdehyd, $\left.\mathrm{CH}_{3} \cdot \mathrm{CHOH} \cdot \mathrm{CH}_{2} \cdot \mathrm{COH}\right)$, der sich zu n-Buttersäure $\left(\mathrm{CH}_{3} \cdot \mathrm{CH}_{2} \cdot\right.$ $\mathrm{CH}_{2} \cdot \mathrm{COOH}$ ); umlagert. Dieser letztere Vorgang, der wahrscheinlich auch für den Aufbau der Fette von Bedeutung ist, stellt zweifellos eine kombinierte Oxydations- und Reduktions-Reaktion dar, die wir durch. sukzessive Anwendung von Silbernitrat und Jodwasserstoff in vitro reproduzieren können.

1) Vgl. C. Neuberg u. E. Reirfurth, Biochem.Zeitschr. 89, 365 ff. (1918).

2) Vgl. auch C. Ne uberg u. E. Reinfurth, Biochem. Zeitschr. 92, 96 ff. (1918).

3) Vgl. B. Leathes, Erg. d. Physiol. 8, 356 ff. (1909). Azetaldehyd bei der Buttersäuregärung wurde nachgewiesen von $\mathrm{C}$. N e u ber $\mathrm{g}$, Biochem. Zeitschr. 96 (1919). 
Auch die übrigen bekannten Atmungsprozesse besonderer Art bieten einer Deutung auf Grundlage der elektrolytischen Atmungstheorie keine Schwierigkeiten; fraglich, aber durchaus nicht unerklärlich wäre es nur, ob bei der Bildung von Milchsäure aus Zucker die gekoppelte Oxydations- und Reduktions-Reaktion vorliegt. Nun hat aber Rubner ${ }^{1}$ ) gezeigt, daß bei Milchsäurebakterien nur etwa die Hälfte der Wärmeproduktion auf Rechnung Milchsäurebildung zu setzen ist, so daß es überhaupt unsicher erscheint, ob sie die eigentliche Energiequelle des Lebens oder nur eine Vorbereitungsstufe darstellt.

Bei den denitrifizierenden Bakterien muß Salpetersäure die Rolle des atmosphärischen Sauerstoffs vertreten, was höchstwahrscheinlich durch Enzyme bewirkt wird; ist doch schon das mehrfach erwähnte Aldehydferment imstande, $\mathrm{HNO}_{3}$ zu reduzieren. Bei den nitrifizierenden, den Schwefel- und den Eisenbakterien würden wiederum anorganische Stoffe die Rolle des Traubenzuckers vertreten; und den einfachsten Stoffwechsel hätten die Wasserstoffbakterien, bei denen nach der elektrolytischen Atmungstheorie molekularer Sauerstoff sich mit naszierendem Wasserstoff, molekularer Wasserstoff mit naszierendem Sauerstoff verbinden würde.

In all diesen Fällen mub es zunächst offen bleiben, in welchem Umfang Enzyme in den Vorgang der Depolarisation eingreifen. Das wird dann nicht unbedingt nötig sein, wenn die Depolarisation auch ohne sie, zwar mit Hilfe von Fe-Ionen, die erforderliche sehr geringe Reaktionsgeschwindigkeit aufweist. So ist es durchaus denkbar, dab in der Reaktionskette des oxydativen. Abbaus derartige nicht enzymatische Glieder vorhanden sind, und daß es daran liegt, wenn alle Versuche, derartige Reaktionen mit leblosen Organpräparaten in vollem Umfange zu reproduzieren, gescheitert sind. Tatsächlich scheint es sich wenigstens in einem bestimmten Fall so zu verhalten, nämlich in der sogenannten alkoholischen Gärung der Aminosäuren, die von Ehrlich ${ }^{2}$ ) entdeckt wurde, und sich in seinen sowie in allen späteren Versuchen als untrennbar vom Leben erwies. Die Reaktion wird in ihrer Gesamtheit durch folgende Gleichung ausgedrückt:

$$
\text { R. } \mathrm{CH} \mathrm{NH}_{2} \cdot \mathrm{COOH}+\mathrm{H}_{2} \mathrm{O}=\mathrm{R} \mathrm{CH}_{2} \mathrm{OH}+\mathrm{NH}_{3}+\mathrm{CO}_{2} \text {. }
$$

Da aber, wie die Untersuchungen von Neubauer u. Fromberz ${ }^{3}$ ) gezeigt haben, der Abbau der Aminosäuren bei der Hefe ebenso wie

1) M. Rubner, Archiv f. Hygiene 57, 252 (1906).

2) F. Ehrlich, Biochem. Zeitschr. 2, 52 (1906).

3) O. Ne ubauer u. K. From herz, Zeitschr. f. physiol. Chem. 70, 326 (1911). 
im Tierkörper auf dem Wege über die Ketosäuren erfolgt, ist anzunehmen, daß die ganze Reaktion sich in folgenden drei Stufen abspielt (vgl. Ne uberg, Gärungsvorgänge usw., S. 32 ff.):
l) $\mathrm{R} \cdot \mathrm{CHNH} \mathrm{NH}_{2} \cdot \mathrm{COOH}+\mathrm{O}=\mathrm{R} \cdot \mathrm{CO} \cdot \mathrm{COOH}+\mathrm{NH}_{3}$.
II) $\mathrm{R} \cdot \mathrm{CO} \cdot \mathrm{COOH}=\mathrm{R} \cdot \mathrm{COH}+\mathrm{CO}_{2}$.
III) $\mathrm{R} \cdot \mathrm{COH}+\mathrm{H}_{2}=\mathrm{RCH}_{2} \mathrm{OH}$.

Nun stellt Reaktion II die bekannte Neuberg'sche Karboxylasewirkung dar, III einen Typus von Reaktionen, der nach Neuberg's Untersuchungen, wie aus der dabei stattfindenden asymmetrischen Reduktion -hervorgeht, gleichfalls auf enzymatischem Wege erfolgt. Demnach würde die oxydative Desaminierung unter Ketosäurebildung der Prozeb sein, der sich nicht vom Leben trennen läßt. Es ist dabei zu beachten, daß dieser Vorgang nach Ehrlich's. Ergebnissen eng mit der Zuckergärung verknüpit ist, also vermutlich mit einem zu deren Reaktionskette gehörigen Reduktionsvorgang gekoppelt. Da die Hefe ein für Enzymdarstellung äußerst günstiges und methodisch sehr gut durchgearbeitetẹ Objekt darstellt, möchte man annehmen, daß in diesem Falle die Reaktion wirklich ohne Enzym verläuft. Ihre Durchführung durch kapillarelektrolytische Oxydation und Reduktion würde aber auf keinerlei Schwierigkeiten stoßen.

Unsere Auffassung macht auch ohne weiteres eine an sich sehr auffällige Tatsache verständlich: daß z. B. eine lebende Zelle auch in Abwesenheit von $O$ das leicht reduzierbare Methylenblau durchaus nicht in allen Fällen angreift. Pfeffer hat daraus geschlossen, daß eine allgemeine, gegen alle Stoffe gerichtete Reduktionswirkung in der Zelle nicht besteht ${ }^{1}$ ). Im Lichte der elektrolytischen Atmungstheorie würde das so zu verstehen sein, daß bei anaerober Atmung Methylenblau zwar neben anderen Stoffen (Azetaldehyd!) reduziert werden wird, daß aber mangels irgendwelcher Lokalisation die Leukobase ihrerseits wieder der elektrolytischen Oxydation anheimfallen muß. So wird verständlich, daß eine Entfärbung des Methylenblaus in der Zelle trotz anaeroben Stoffwechsels nicht einzutreten braucht, daß aber seine Anwesenheit, wie Palladin beobachtete die Gärungsintensität herabsetzt, ebenso wie nach Meyerh of oft die der Atmung. Auch hier fällt die Tatsache auf, daß ein allgemeines, wahlloses Oxydationsvermögen nicht besteht (Pfeffer, loc. cit.). Zyanin, das sehr leicht zu einer farblosen Verbindung oxydiert wird, bleibt im Protaplasma unangetastet, wird aber sofort entfärbt, wenn die Zelle zur Aufnahme

1) W. Pf effer, Abhand1. d. K. S. Ges. d. Wiss. Math.- phys. K1. 1889, S. 513. 
von Wasserstoffsuperoxyd veranlaßt wird. Pfeffer hat daraus die unabweisliche Schlubfolgerung gezogen, daß die Sauerstoffaktivierung nicht die unmittelbare Ursache der physiologischen Verbrennung sein kann; sonst müßte sie sich in erster Linie auf so leicht oxydierbare Substanzen erstrecken, wie Zyanin. Nach unserer Auffassung wird es sich mit diesem Farbstoff genau so verhalten, wie mit dem Methylenblau; er wird einerseits oxydiert, anderseits regeneriert werden; er wird störend in den Atmungsstoffwechsel eingreifen, ohne daß eine Entfärbung uns davon Kunde gibt. Ein einseitig gerichteter Reaktionsverlauf wird nur diejenigen Stoffe erfassen, auf die bestimmt lokalisierte Enzyme wirken, so wie wir es oben ausführlich dargestellt haben. Wir haben ein vollständiges Analogon dazu in zahlreichen Fällen der präparativen Elektrolyse, in denen wir gezwungen sind, durch Diaphragmen das erwünschte Produkt elektrolytischer Oxydation oder Reduktion an der einen Elektrode zu lokalisieren, damit es nicht an der entgegengesetzten wieder zerstört wird.

Es sei noch in aller Kürze auf eine Folgerung der Theorie hingewiesen, die sich möglicherweise als heuristisch bedeutsam bewähren könnte. Die physiologische Oxydation ist nach unserer Auffassung ein äußerst gelinder Prozeb, weil sie bei sehr niederem (wenig positivem) Oxydationspotential, also bei geringer Sauerstoffkonzentration vor sich geht, wobei die Langsamkeit der Reaktion durch die große wirksame Oberfläche ausgeglichen wird. Nun hat sich hauptsächlich in den Untersuchungen $\mathrm{N}$ e ub e rg's gezeigt, daß gelinde Oxydationen, z. B. solche, die man mit Hilfe von $\mathrm{H}_{2} \mathrm{O}_{2}$ und $\mathrm{Fe}$-lonen vornimmt eine große Aehnlichkeit mit biochemischen Vorgängen haben; aber selbst derartige Oxydationsprozesse sind heftig im Vergleich zu denen, die wir im Protoplasma annehmen, denn wenn bei dieser O-Uebertragung das Potential des Katalysators in Betracht kommt, so würde es in diesem Falle, an der normalen H-Elektrode gemessen, noch immer ca. $+0,6-+0,7 \mathrm{~V}$ betragen. Durch Verwendung negativerer Ionengemische wie Ferro-Ferrizyanid oder Uranyl-Uranisalz können wir diese Oxydationspotentiale abstufen, und es würde sich nun fragen, ob sie dadurch bei abnehmender Geschwindigkeit sich noch weiterhin in ihrem Charakter den biochemischen Prozessen nähern. Namentlich für den Abbau der höheren Fettsäuren der dem Verständnis so große Schwierigkeiten bietet, könnte die Berücksichtigung dieses Gesichtspunktes von Bedeutung sein: 


\section{Die Bedeutung der Elektroosmose für die Energietransformation im Protoplasma.}
a) Allgemeines.

Wir haben im ersten Teil dieser Arbeit gezeigt, daß die kapillarelektrischen Erscheinungen im Protoplasma imstande sind, das Rätselhafte der physiologischen Oxydation zu erklären. Denn durch sie tritt anstelle des reaktionsträgen atmosphärischen der naszierende elektrolytische Sauerstoff, während jener seinerseits durch naszierenden Wasserstoff und nicht durch die reaktionsträgen organischen Substanzen in den AtmungsprozeB hineingezogen wird. Nun haben wir die Frage zu prüfen, inwieweit die elektrolytische Atmungstheorie imstande ist, auch die offenen Probleme der physiologischen Energetik zu lösen.

Elektroosmotische Erscheinungen sind schon wiederholt zur Erklärung physiologischer Prozesse herangezogen worden. Namentlich haben $\mathrm{Girard}{ }^{1}$ ) und Bernstein ${ }^{2}$ ) erzwungene Wasserbewegungen auf diesem Wege zu deuten versucht. Bernstein hat diesen Versuch (loc. cit., S. 162 ff.) durch ein Experiment illustriert, dessen Analyse für unsere Betrachtungen außerordentlich lehrreich ist. Eine nach $P$ f e f fer $s$ Verfahren mit Ferrozyankupfermembran versehene Tonzelle wurde "innen mit einer 0,5 prozentigen Lösung von $\mathrm{K}_{4} \mathrm{FeCy}_{6}$ gefüllt, mit einem offenen U-förmigen dünnen Mamometerrohr durch einen Stopfen dicht verbunden und in eine $0,5-0,525$ prozentigen Lösung von $\mathrm{CuSO}_{4}$ hineingestellt. Die $\mathrm{CuSO}_{4}$-Lösung hatte einen um ein geringes höheren osmotischen Druck, als die $\mathrm{K}_{4} \mathrm{FeC}_{6}$-Lösung, so daß vermöge der Diffusion. Wasser von, innen nach außen hätte wandern müssen. Der osmotische Druck wurde nach der Gefrierpunktsmethode bestimmt; nichtsdestoweniger war im Manometer der Tonzelle sehr bald eine deutliche Drucksteigerung zu beobachten“.'Bernstein erklärt diese Flüssigkeitsbewegung für eine Folge der zwischen beiden Seiten der Membran herrschenden Potentialdifferenz, die wie das Schema in Fig. 53, S. 160, loc. cit. zeigt, positiv geladene Wasserteilchen von der positiven nach der negativen Seite treiben soll.

Daß diese Auffassung thermodynamisch anfechtbar ist, hat zuerst $\mathrm{Höber}$ betont (loc. cit., S. 255); denn da die Membran als undurchlässig für die in Frage kommenden Ionen angenommen wird, ist ein Ausgleich irgend eines Diffusionspotentials nicht möglich, das imstande

1) Vgl. R. Höber, Physikalische Chemie der Zelle und der Gewebe, 4. Aufl. (1914), S. $250 \mathrm{ff}$.

2) J. Bernstein, Elektrobiologie (Braunschweig 1912), S. 156 ff. 
wäre, die für die elektroosmotische Wasserbewegung aufzuwendene Arbeit zu leisten. Freundlich ${ }^{1}$ ) hat dann den Bernstein'schen Versuch einer eingehenden Analyse unterworfen und kommt vor allem zu dem Ergebnis, daß Potentialdifferenzen allein zur Unterhaltung der Wasserbewegung nicht genügen, daß vielmehr dazu die Existenz lokaler Membranströme nötig ist, in der Art wie wir sie auch als Ursache der Atmung im Protoplasma angenommen haben.

Für das Zustandekommen dieser Membranströme erörtert Fre und li ch zwei Möglichkeiten; 1 . daß tatsächlich die Teilchen der Membran für die Ionen der Salzlösungen' nicht völlig inpermeabel sind und daß deren Diffusion die erforderliche Arbeit leistet; oder 2., daß die zu beiden Seiten der Membran befindlichen Stoffe chemisch miteinander reagieren. Diese Deutung beansprucht unser besonderes Interesse, und wir gehen darum näher auf sie ein. Sie geht im Prinzip auf die Erklärung zurück, die Ostwald dem sogenannten Becquerelphänomen gegeben hat. „Es handelt sich dabei um folgende Erscheinung: Bringt man eine z. B. mit $\mathrm{Cu}\left(\mathrm{NO}_{3}\right)_{2}$ gefüllte Tonzelle in eine Lösung von $\mathrm{Na}_{2} \mathrm{~S}$, so scheiden sich an der Tonzelle im Laufe der Zeit $\mathrm{Cu}$-kristalle ab. Vorbedingung für das Auftreten dieser Erscheinung ist nach Ostwald einmal die Bildung eines schwerlöslichen Niederschlages als halbdurchlässiger Membran in den Poren der Tonzelle, in diesem Fall also von $\mathrm{CuS}$; und zwar nimmt er an, daß dieses für $\mathrm{Cu}$ und $\mathrm{S}$-Ion undurchlässig ist, durchlässig für $\mathrm{NO}_{3}$ und $\mathrm{Na}-\mathrm{Ion}$ (so daß also Membranpotentiale auftreten müssen; N). Zweite Vorbedingung sei die Möglichkeit einer chemischen Reaktion zwischen den beiden gelösten Stoffen: S-Ion kann zu $\mathrm{S}_{2}$-Ion oxydiert werden, während $\mathrm{Cu}$-Ion zu $\mathrm{Cu}$ reduziert wird. Es tritt dann $\mathrm{NO}_{3}$-Ion durch die als sehr dünn angenommene $\mathrm{Cu}$ S-Membran; beim Uebergang von $\mathrm{S}$-Ion uud $\mathrm{S}_{2}$-Ion nach der Gleichung.

$$
2 \mathrm{~S}^{\prime \prime}+4 \mathrm{Na} \cdot=\mathrm{S}_{2}{ }^{\prime \prime}+2 \mathrm{Na} \cdot+2 \Theta+2 \mathrm{Na} \cdot
$$

werden $2 \mathrm{Na}$-Ionen frei, die durch 2 von der durchgetretenen $\mathrm{NO}_{3}$-Ionen neutralisiert werden. Die beiden freigewordenen negativen Ladungen wandern durch die Wand der Membrankapillaren, entladen auf der anderen Seite $\mathrm{Cu}$-lonen zu metallischem $\mathrm{Cu}$ und das Spiel kann von neuem beginnen " (Freundlich, loc. cit.). Freundlich fährt dann fort „man braucht jetzt wiederum bloß anzunehmen, daß der so entstandene Lokalstrom elektroosmotisch Wasser durch die Membran treibt und man hat die Möglichkeit einer abnormen Osmose". Diese

1) H. Freundlich, Koll.-Zeitschr. 18, 11 ff. (1916). 
Forderung Freundlichs wird dann erfüllt sein, wenn wie wir in Anlehnung an Coehn annahmen, positiv geladene Wasserteilchen von der Kupfersulfat- nach der Natriumsulfidseite getrieben werden, anstelle der negativen Ladungen, die in Ostwald's Schema im entgegengesetzt gerichtetem Sinne durch die Membransubstanz wandern. In dieser aber würden die Ionen des Wassers die Rolle der Ladungsträger spielen. Bernsteins Experiment erklärt nun Freundlich auf dieser Grundlage durch die Annahme, daß dabei $\mathrm{K}_{4} \mathrm{Fe} \mathrm{Cy}_{6}$ oxydiert und $\mathrm{CuS} \mathrm{O}_{4}$ reduziert wird.

Ueber die große biologische Bedeutung dieses Erklärungsversuchs ist sich Freundlich klar, weil, wie er betont, einerseits bei der geringen Dicke der physiologischen Membranen die Bedingungen für die Erzeugung von Lokalströmen äußerst günstig sind, und da andererseits „Oxydationsvorgänge für das Leben immer wieder von Bedeutung sind, kann leicht die Bedingung erfüllt sein, daß die Flüssigkeit auf der einen Seite der Membran als Oxydationsmittel, auf der anderen Seite als Reduktionsmittel wirkt." Auf der gleichen allgemeinen Grundlage wie dieser Erklärungsversuch ruht die elektrolytische Atmungstheorie; jedoch ist in ihr als Zwischenglied noch die stenolytische Wasserzersetzung eingeschaltet; und da drängt sich naturgemäß die Frage auf, warum denn in der Atmung dieser Vorgang die entscheidende Rolle spielen soll, während wir ihm in den Deutungen Ostwald's und Freundlich's nicht begegnen. Der Unterschied ist folgender: in jenen Fällen befinden sich zu beiden Seiten der Membran elektrochemisch reaktionsfähige Stoffe, deren Ionen durch die kapillarelektrisch erzeugten Membranströme entladen werden; nach dem Prinzip, daf immer zuerst die am leichtesten entladbaren Ionen in Reaktion treten, bleiben die Ionen des Wassers verschont. Zu beiden Seiten der physiologischen Membran aber befinden sich träge Reduktions- und Oxydationsmittel, organische Substanzen und atmosphärischer Sauerstoff, und so erfolgt zunächst die Entladung der lonen des Wassers und erst sekundär können die Atmungsmaterialien durch die naszierenden Produkte der Elektrolyse in die Reaktion einbezogen werden.

An und für sich würde die von Freundlich entwickelte Vorstellung einen einfacheren Zusammenhang zwischen Atmung und elektroosmotischen Vorgängen im Protoplasma zulassen. Einseitige Milchsäurebildung könnte, wie oben angenommen, die erforderliche Spannung herstellen; wenn zu ihrem Ausgleich die Milchsäure-Anionen abwandern und auf dem Wege, zusammen mit den entgegenwandernden 
H-lonen, durch einen rein enzymatischen Prozeß verbrannt würden, dann müßte dauernde Nachlieferung der Michsäure-Ionen auch ohne Dazwischenkunft der Stenolyse einen dauernden Strom unterhaiten, der elektroosmotisch wirksam werden könnte. Aber diese Auffassung würde den physikalischen und physiologisch-chemischen Bedingungen im Protoplasma nicht Rechnung tragen, indem sie die Notwendigkeit des Eintritts stenolytischer Wasserzersetzung und ihres Eingreifens in den Gesantstoffwechsel außer Acht liefe und aus diesem Grunde wäre sie auch nicht imstande, das Zustandekommen der physiologischen Verbrennung zu erklären.

Wenn wir diese Betrachtung fortführen, gelangen wir noch $z u$ einer anderen Seite des Problems: Es besteht nämlich zwischen dem zuletzt skizzierten Zusammenhang von. Atmung und Elektroosmose und dem, der sich aus der elektrolytischen Atmungstheorie ergibt, noch ein ganz bedeutender Unterschied hinsichtlich des Ausnutzungskoeffizienten. Die vom Strom geleistete Arbeit ist gleich dem. Produkt aus seiner Spannung und der von ihm transportierten Elektrizitätsmenge. Die erstere wäre gegeben durch die Milchsäurekonzentration und die Eigenschaften der Membran, und sei für alle jetzt zu betrachtenden Fälle als gleich angenommen. Die Elektrizitätsmenge wäre bei einfacher Verbrennung eines bestimmten Milchsäurequantums gleich der Summe von positiven Ladungen, die durch die Elektroosmose zur Neutralisation der entstandenen Anionen in Bewegung gesetzt würde, also für jedes Milchsäure-Ion eine Ionen-Ladung. Bei elektrolytischer Verbrennung käme aber die Ladungsmenge in Frage, die die völlige Oxydation der Milchsäure erfordert, also für jedes Anion sechs: ceteris paribus wäre dies also eine sechsmal so ökonomische Ausnutzung der stromliefernden Reaktion.

Damit kommen wir zur Frage nach der absoluten Größe des ökonomischen Koeffizienten, der sich auf diesem Wege der Energietransformation überhaupt erreichen läßt. Wir nehmen dabei an, daß der gesamte Verbrennungsprozeß der bei der Atmung mitwirkenden Menge organischer Substanz auf elektrolytischem Wege vor sich geht; dann bildet das dazu nötige Sauerstoffquantum das Maß für den dabei erzeugten Strom. Die Stromarbeit ist dann gleich dem Produkt dieser Menge und der Spannung, durch die der Strom erzengt wird, während die freie Energie des Verbrennungsprozesses durch das Produkt der gleichen Strommenge mit der maximalen Spannung die theoretisch dabei exzeugt werden könnte, also dem Oxydationspotential der organischen Substanz, ausgedrückt wird. Diesen Wert können wir 
zwar nicht messen, aber berechnen; denn nach den auf Grund des Nernst'schen Theorems von $B$ aron und Polány $\mathbf{i}^{1}$ ) angestellten Berechnungen ist die freie Energie dieser Verbrennung tatsächlich etwa gleich dem mechanischen Aequivalent der dabei erzeugten Wärme, so wie es die Physiologie bisher stillschweigend angenommen hat.

$\mathrm{Zu}$ den fraglichem Oxydations-Potential gelangen wir auf folgendem Wege. Wir gehen davon aus, daß eine Ampèrestunde gleich 3600 Coul dem Verbrauch von $0,3 \mathrm{~g}$ Sauerstoff entsprechen. Nun braucht $1 \mathrm{~g}$ Glukase zur Verbrennung 1,07 $\mathrm{g} 0$ und erzeugt dabei $3760 \mathrm{cal} ; 1,07 \mathrm{~g} 0$ entsprechen aber $3600 \times 1,07: 0,2 \mathrm{cal}=12800 \mathrm{cal}$.

Die Einheit der elektrischen Arbeit 1 Volt $\times 1$ Coul entspricht aber $0,2368 \mathrm{cal}$; ist $\varepsilon$ der gesuchte Wert des Oxydationspotentials in Volt, so ergibt sich dessen Größe aus der Gleichung:

$$
\begin{aligned}
& \varepsilon \times 12840 \mathrm{Coul}=3760: 0,2368 \mathrm{cal}=14611 \mathrm{cal} \\
& \varepsilon=14611: 12840=1,23 \text { Volt. }
\end{aligned}
$$

Der Nutzeffekt der Zellströme würde also durch das Verhältnis $\frac{\varepsilon_{1}}{\varepsilon}$ ausgedrückt werden, wenn $\varepsilon_{1}$ deren Spannung bedeutet; von ihrer Größe hängt also der ökonomische Koeffizient der auf diesem Wege verwertbaren Energie ab.

Schreiben wir im Sinne unserer Theorie den elektrolytischen Erscheinungen eine allgemeinere Bedeutung zu, dann werden wir für $\varepsilon_{1}$ den maximalen Wert einsetzen, der überhaupt beobachtet ist, also ca. 0,12 Volt, zumal da die Differenzen der Säurekonzentration denen die Hauptrolle bei der Entstehung der Membranströme zuzuschreiben wäre, ganz besonders für die Erzeugung relativ hoher Spannungen geeignet sind. Bei dieser Erwägung ist $z u$ beachten, daß, worauf Bernstein schon hingewiesen hat, die elektrophysiologische Messung nur im Nebenschluß eines in sich kurz geschlossenen Stromes erfolgt, also niemals dessen Spannungswert in voller Höhe erkennen lassen wird. Wir würden also ohne weiteres zur Annahme von Nutzeffekten von über 10 Prozent gelangen, die wohl in den allermeisten Fällen ausreichen; unzureichend wären sie aber, wenn wir für die Erzeugung der Muskelkraft eine elektroosmotische Theorie aufstellen wollten, ein Punkt, auf den wir noch ausführlich zu sprechen kommen.

1) A. Baron u. M. Polányi, Biochem. Zeitschr. 53, 1 ff. (1913). 
b) Die Rolle der Elektroosmose in den Resorptionsund Sekretionsvorgängen.

Nachdem der Zusammenhang zwischen Atmung und Elektroosmose physikalisch sowohl wie physiologisch hinreichend klargelegt erscheint, können wir an die Erörterung der Frage gehen, welche Rolle den elektrischen Kräften bei der Bewegung, von Wasser und gelösten Stoffen zuzuschreiben ist.

Wenn man wie es Höber (loc. cit., S. 606 ff.) in seiner zusammenfassenden Darstellung tut, den Flüssigkeitsstrom betrachtet, der aus den Höhlen des Intestinaltraktes durch die Blut- und Lymphbahnen, durch die Organe des Körpers, aus diesen wieder durch die Leitungsbahnen zu den Drüsen führt und durch deren Ausführungsgänge den Körper wieder verläßt, so sieht man, wie zu den osmotischen und Diffusionskräften, die nach Maßgabe der herrschenden Bedingungen im Organismus in gleicher Weise tätig sein müssen, wie in jedem leblosen System, noch eine besondere Triebkraft kommt, um die Leistungen zu vollbringen, für die Diffusion und Osmose allein nicht genügen. Die Darmwand hat z. B. die Fähigkeit, auch im überlebenden Zustande Flüssigkeit ohne osmotisches Druckgefälle von der Innennach der Außenseite zu schaffen; die Drüsen stellen Sekrete dar, die oft im Vergleich mit dem Blut hypotonisch 'sind, so daß bei ihrer Bildung das Wasser sich von der konzentrierteren nach der verdünnteren Lösung bewegt, und vor allem haben die Drüsenzellen vielfach die Fähigkeit, im Sekret Stoffe in einer Konzentration anzusammeln, die die im Blute herrschende um ein Erhebliches übertrifft. Auch in der Pflanze spielen analoge Triebkräfte eine Rolle. Wenn wir sie bezüglich des Austauschs gelöster Stoffe von Zelle zu Zelle nicht so leicht nachweisen können, so gibt uns doch der Blutungsdruck, der das von den Wurzeln aus dem Boden aufgenommene Wasser mit bedeutender Kraft in die Leitungsbahnen treiben kann, davon ein äußerst anschauliches Bild.

Das Wesen dieser Triebkraft erblicken nun Girard und Bernstein in elektroosmotischen Vorgängen.

Wir wollen nun darangehen, zu untersuchen, was sich aus den entwickelten Vorstellungen für Folgerungen hinsichtlich der Bewegung von Wasser und gelösten Stoffen ergeben. Wir gehen dabei am besten von der Betrachtung der hydrostatischen Verhältnisse der Pflanzenzelle aus, die nach Bernstein (loc. cit. S. 174) von den elektroosmotischen Erscheinungen beeinflußt werden sollen. Dabei ist vor allen Dingen 
zu beachten, daß in diesem speziellen Falle die Berücksichtigung dieser Prozesse unter allen Umständen nötig ist, gleichgültig, ob man sich im allgemeinen auf den Boden der elektrolytischen Atmungstheorie stellen will oder nicht. Wir haben ja schon betont, daß nach Loeb und Beutner's Ergebnissen über den Einfluß von Salz- und Säurekonzentration auf die elektrischen Potentiale der Pflanzenorgane in jeder Zelle eine ganz beträchtliche Spannungsdifferenz zwischen der äußeren Plasmamembran und der Vakuolenhaut, die an eine salzreiche und oft sauer reagierende Flüssigkeit grenzt, bestehen muB und zwar so, daß die Innenseite der Zelle gegen die äubere positiv geladen ist. Da die Plasmaschicht im ganzen ein Kapillarsystem darstellt, müssen sich in ihr unter Stenolyse des Wassers Lokalströme ausbilden. Die für ihre dauernde Erhaltung nötige Depolarisation ist aber ohne weiteres gewährleistet, denn der an der Außenseite entstehende Wasserstoff findet atmosphärischen Sauerstoff und außerdem Oxydationsenzyme vor, der naszierende Wasserstoff an der Vakuolenhaut aber allezeit reduzierende Substanzen im Zellsaft: organische Säuren, Chromogene usw.

Es ist also anzunehmen, daß unter allen Umständen eine elektrisch betriebene, einwärts gerichtete Wasserbewegung erfolgt; über ihren Umfang und ihre Wirkung müssen wir uns jedoch durch eine besondere Ueberlegung klar werden. $\mathrm{Zu}$ diesem Zwecke wollen wir die Erscheinungen der Elektroosmose, so wie sie sich außerhalb des Organismus abspielen, etwas näher ins Auge fassen. An und für sich können derartige Wasserbewegungen sehr leicht bedeutende Intensität erreichen. Betrachten wir irgend ein empirisches Beispiel, so zeigt es sich etwa, daß in einem bestimmten Falle ein Strom von 2,2 Amp. beim Durchtritt durch eine Schicht breigen Torfs in einer halben Stunde zwei Liter Wasser in kathodischer Richtung in Bewegung setzte, d. h. $6000 \mathrm{mal}$ soviel, als die gleiche Strommenge elektrolytisch zu zersetzen vermag ${ }^{1}$ ). Das besagt, daß hier als positive Elektrizitätsträger Wasserteilchen von sehr bedeutender Größe in Frage kommen, was ja mit dem oben angeführten Schlußfolgerungen Lenard's im Einklang steht. Daneben kommen für den Stromdurchgang durch die wassergetränkte Masse noch positive $\mathrm{H}^{*}$ - und negative $\mathrm{OH}^{\prime}$-Ionen in Betracht. Der positive nach der Kathode gerichtete Strom verteilt sich also auf Wasserteilchen und auf Kationen; demgemäß sinkt der Effekt der Elektroosmose proportional der spezifischen Leitfähigkeit der Flüssigkeit. Je mehr Kationen vorhanden sind und je leichter sie

1) F. Foerster, Elektrochemie usw. S. 114. 
wandern, um so geringer ist der Stromanteil, dessen Transport den Wasserteilchen zufällt. Das Volumen der vom Strom überführten Wassermenge beträgt nach der von Perrin ein wenig abgeänderten Helmholt $z$ 'schen Formel

$$
\mathrm{v}=\frac{\mathrm{q} \cdot \varepsilon \cdot \mathrm{H} \cdot \mathrm{D}}{4 \pi \cdot \eta}
$$

worin v das übergeführte Volumen, $\varepsilon$ den Potentialsprung zwischen Flüssigkeit und Kapillarenwand, $\mathrm{H}$ das treibende Potentialgefälle, $\mathrm{q}$ den stromdurchflossenen Querschnitt, D die Elektrizitätskonstante der Flüssigkeit, $\eta$ ihre innere Reibung darstellt.

Der erreichte Druck ist durch die Formel gegeben:

$$
\mathrm{p}=\frac{2 \varepsilon \cdot \mathrm{E} \mathrm{D}}{\pi \mathrm{r}^{2}}
$$

wobei noch E die Spannung bedeutet, durch die die Elektroosmose getrieben wird, in unserem Fall also die Potentialdifferenz zwischen Plasma- und Vakuolenhaut, und $\mathrm{r}$ den Radius der Kapillaren. Wir kennen die Werte für $\mathrm{E}$, $\varepsilon$ und $\mathrm{r}$ nicht und können daher keine genaue Berechnung durchführen. Da aber in unserem Falle der Faktor $1: r^{2}$ sehr groß ist, so könnte der elektroosmotische Druck recht bedeutend werden, wenn er nur rein zum Ausdruck käme; das ist aber in Wirklichkeit nicht der Fall.

Die genannte $\mathrm{Helmholtz'sche}$ Formel ist nämlich unter der Voraussetzung abgeleitet, daß, wie z. B. bei Tondiaphragmen, dem elektroosmotischen Einstrom und dem durch den steigenden Innendruck bewirkten Ausstrom, die sich im Gleichgewichtszustand die Wage halten, dieselben Wege zur Verfügung stehen, nämlich die flüssigkeitserfüllten Kapillarräume. Wenn wir es aber, wie im Protoplasma mit stark gequollenen Membranen zu tun haben, dann müssen wir damit rechnen, daß der elektroosmotische Einstrom durch die Kapillaren, der durch Druckfiltration erzeugte Gegenstrom aber außerdem durch die eigentliche Membransubstanz selbst erfolgt. Dann wird in dem sich einstellenden stationären Zustand der Gleichgewichtsdruck bedeutend niedriger sein, als der der Formel entsprechende elektroosmotische Druck, genau so, wie in einer von Rissen durchsetzten halbdurchlässigen Zelle auch der osmotische Druck nicht voll zur Entwickelung kommen wird. In Bernstein's Versuchen ist nun tatsächlich als Maximum des erreichten elektroosmotischen Drucks nur ca. $1 / 30$ Atmosphäre gemessen worden, also eine für die Hydrostatik der Pflanzenzelle ziemlich bedeutungslose Größe. Nun würden der 
Perrin'schen Formel gemäß bei gleicher Membranspannung in der Pflanzenzelle die Verhältnisse insofern günstiger liegen, als die in Betracht kommende Schicht dünner und infolgedessen das Potentialgefälle größer ist. Dem steht aber gegenüber, daß hier die Quellung zweifellos noch weit bedeutender ist als die der Ferrozyankupfermembran; also legt uns sowohl das physikalische Experiment, als die theoretische Erwägung nahe, die Bedeutung des elektroosmotischen Druckes für die Hydrostatik der Pflanzenzelle nur mit grober Vorsicht einzuschätzen, und in gleicher Richtung sprechen die Erfahrungen der Physiologie. Es ist doch eben Tatsache, daB zur Erzeugung und Regulation des Turgordruckes osmotisch wirksame Substanzen in der Vakuolenflüssigkeit angehäuft werden und so weit sich dies beurteilen läßt, stimmt der Größenordnung nach die Menge dieser Stoffe mit dem erzeugten Druck überein. Zu diesem osmotischen Druck treten noch als positive oder negative Summanden niederer Ordnung der Oberflächendruck und der Quellungsdruck des Protoplasmas ${ }^{1}$ ), zu denen sich nun noch der elektroosmotische Druck gesellen wird, ohne dab wir ihm eine entscheidende Rolle zuzuweisen vermöchten.

Aber eine andere Folgerung von wesentlich größerer Tragweite ergibt sich aus unseren Erwägungen. Das scheinbare hydrostatische Gleichgewicht der Pflanzenzelle ist eigentlich ein dynamischer Gleichgewichtszustand, der durch ${ }^{\text {den }}$ unter Arbeitsaufwand bewirkten Einstrom und den entgegenwirkenden Filtrationsstrom aufrecht erhalten wird. Dieser Zustand muB aber mit Notwendigkeit zur Leistung äußerer Arbeit, nämlich zu einseitigem Wassertransport führen, sobald Qualitätsverschiedenheiten des Protoplasmas auf entgegengesetzten Seiten der Zelle auftreten. Jede Aenderung der physikalischen Eigenschaften würde natürlich einerseits den Filtrationswiderstand, andererseits die elektroosmotische Leistungsfähigkeit beeinflussen und da für diese letztere, wie ein Blick auf die Helmholtz'sche Formel lehrt; Faktoren in Betracht kommen, die für den Filtrationswiderstand bedeutungslos sind, so ist a priori zu erwarten, daß irgend eine einseitige Aenderung der Membranqualität das Verhältnis zwischen Druckfiltration und Elektroosmose auf dieser Seite verschiebt. Wenn nun auf der entgegengesetzten Seite der Zelle alles beim Alten bleibt, so wird ein konstanter Wasserstrom sich durch die Zelle bewegen, und zwar nach der Richtung, in welcher die Druckfiltration gegenüber

1) Vgl. W. P.f effer, Plasmahaut und Vakuolen. Abh. d. Math.-phys. Kl. d. K. S. Ges. d. Wiss. 16, 197. 
der Elektroosmose stärker gefördert ist. Damit hätten wir aber eine Erklärung für das Phänomen des Blutens, in welchem das Wasser aus dem Boden durch die Parenchymzellen der Rinde in die Leitungsbahnen gepreßt wird.

Voraussetzung für das elektroosmotische Zustandekommen dieser Erscheinung ist also nach dem Gesagten ein polarer Gegensatz zwischen Außen- und Innenseite der Zellen. Dieser besteht aber tatsächlich und zeigt sich $z$. B. in den Elementen der Schutzscheide von Wurzeln darin, daß Membranverdickungsschichten an der inneren und den seitlichen Flächen, nicht aber nach der Außenseite der Wurzel hin abgelagert werden. Dieser polare Gegensatz muß nun im Plasma so ausgebildet sein, daß bei etwa allseitig gleicher elektroosmotischer Leistung der Filtrationswiderstand an der Innenseite verringert ist; den gleichen Effekt würde natürlich bei allseitig gleichem Filtrationswiderstand ungleichmäBige elektroosmotische Leistungsfähigkeit zur Folge haben.

Tatsächlich ist diese Erklärung ohne irgend welche Schwierigkeiten imstande, sowohl die Größe der Blutungsmenge als des Blutungsdrucks zu erklären. Dieser letztere würde dem Ergebnis unserer Betrachtungen gemäß keineswegs nach der $\mathrm{Helmholtz}$ 'schen Formel $z u$ berechnen sein, sondern einen ganz anderen, niedrigeren Wert annehmen. Wenn, wie es mir am wahrscheinlichsten vorkommt, der Blutungsdruck auf ungleichseitigem Filtrationswiderstand beruht, dann stelit er eben das $\mathrm{MaB}$ dar, um das der Filtrationsdruck einseitig erhöht werden muß, wenn er allseitig gleiche Leistung erzeugen und so den einseitigen Wassertransport zum Stillstand bringen soll. Betrüge nun der wirkende Filtrationsdruck, d. h. der osmotische Druck der Zelle, 5 Atmosphären und würde dabei ein Blutungsdruck von 1 Atmosphäre erzeugt, so würde das bedeuten, daß der Filtrationswiderstand auf der Innenseite der Zellen $5 / 6$ desjenigen auf der Außenseite beträgt; denn man brauchte ihm nur $1 / 5$ hinzuzufügen, um einen allseitig gleichen Filtrationseffekt $z u$ erzeugen: Unter diesen Umständen bietet das Vorkommen von Blutungsdrucken von $2-3$ Atmosphären nichts Ueberraschendes.

Fassen wir das Problem der Blutungsmenge ins Auge, so ist dabei zu berücksichtigen, dab jedes elektroosmotisch transportierte Wasserteilchen eine bestimmte Elektrizitätsmenge erfordert; daß diese bei der Größe der Ladungsträger verhältnismäßig gering ist, haben wir gesehen und wir wollen versuchen, die Zahlen, die wir an dem Beispiel des Torfbreies kennengelernt haben, auf die Verhältnisse in der Pflanze zu übertragen. $1 \mathrm{~g}$ lebhaft atmender Pflanzensubstanz 
verbraucht in der Stunde ca. 0,3 $\mathrm{mg}$ Sauerstoff; das würde einer Stromstärke von 1 Milliampère entsprechen, und dadurch würde auf Grund des erwähnten Beispiels berechnet ein Wassertransport von $6 \mathrm{ccm}$ in der Stunde bewirkt werden können. Wenn nun z. B. eine Palme wie Caryota urens in der Stunde ca. 2 Liter Wasser ausströmen läßt, so würde das die Atmungstätigkeit von ca. $350 \mathrm{~g}$ Pflanzensubstanz beanspruchen, also nur eines geringen Bruchteiles des Wurzelsystems, das einem so mächtigen Baum zur Verfügung steht; oder wenn ein Blatt von Colocasia antiquorum in einer Nacht $100 \mathrm{~g}$ Wasser ausspritzt, also ca. $10 \mathrm{~g}$ pro Stunde, so wïrde dieses Blatt etwa die Atmungstätigkeit von nur $2 \mathrm{~g}$ Wurzelsystem brauchen. Wir sehen also, daß die Blutungsmenge der elektroosmotischen Theorie des Blutens auch dann keine Schwierigkeiten entgegenstellt, wenn man in Erwägung zieht, daß wahrscheinlich nur ein Teil der in der Atmung freiwerdenden Arbeit von den druckerzeugenden Zellen zu diesem Zwecke verwandt wird.

Das gleiche Erklärungsprinzip ist natürlich auch auf diejenigen Fälle anwendbar, in denen im Tierkörper das Wasser sich vom Orte niederen zum Orte höheren Drucks bewegt, also z. B. auf die Ausscheidung von Sekreten, die im Vergleich zum Blut hypotonisch sind; denn es ist ja vollkommen gleichgültig, ob die Kraft, die das Wasser in die sezernierende Zelle zurückzutreiben sucht und durch deren Tätigkeit überwunden wird, auf hydrostatischen oder auf osmotischen Druckdifferenzen beruht.

Nun ruft aber im Tierkörper die an die Lebenstätigkeit gebundene Triebkraft der Resorption und Sekretionsvorgänge nicht nur die Bewegung von Wasser hervor, sie bewirkt vielmehr auch die Resorption von Lösungen ohne osmotische Druckdifferenz und die Sekretion von gelösten Stoffen gegen eine solche; der Betrachtung dieser Erscheinung wollen wir uns nunmehr zuwenden.

Wir können diesen Fall so ansehen, als ob gelöste Stoffe unabhängig von einer Flüssigkeitsbewegung sich dem Konzentrationsgefälle entgegenbewegten. Dies tun im stromdurchflossenen Elektrolyten die Ionen; und während für die abnorme Osmose, also für die Wasserbewegung gegen das Druckgefälle außer der Elektroosmose immerhin noch andere Kräfte zur Erklärung herangezogen werden könnten (), so scheint mir die Bewegung gelöster Stoffe gegen das

1) Vgl. W. Pf effer, Stud. z. Energetik, Abh. d. K. S. Ges. d. Wiss. Math.phys. KI. 19, 265 (1892); L.J ost, Pflanzenphysiologie 3. Aufl. (1913). 
Diffusionsgleichgewicht im elektrischen Strom das einzige physikalisch verständliche Phänomen dieser Art zu sein. Ich will im folgenden diesen Vorgang kurzweg als "Elektrodiffusion" bezeichnen. Wir entwickeln zuerst die theoretischen Forderungen, die zum Zweck einer Erklärung der sekretorischen Leistung gestellt werden müssen und vergleichen sie dann mit den Ergebnissen des Experiments. Kehren wir zunächst zur Betrachtung der stromdurchflossenen Kapillare zurück. In ihr verteilt sich, wie wir gesehen haben, sofern reines Wasser vorliegt, der positive Strom auf die positiv geladenen Wasserteilchen und die einzig vorhandenen Kationen : die Ionen des Wasserstoffs. Das Gleiche wird der Fall sein, wenn die Membran von einer Salzlösung bespült wird, für die sie undurchlässig ist. Wir müssen ja damit rechnen, daß das in den Membrankapillaren enthaltene Wasser durch die Teilchen der Membransubstanz, in deren Wirkungssphäre es sich befindet, besondere Lösungseigenschaften erhält. Sonst wäre es unmöglich, daß eine wasserdurchtränkte Membran für wasserlösliche Stoffe undurchlässig ist. Ist das z. B. für das Na-Ion der Fall, so würde das Wasser in den Kapillaren, trotz der Berührung der Membran mit einer $\mathrm{NaCl}$-Lösung, keine Na-Ionen enthalten. Haben wir es aber z. B. mit einer Nierenzelle zu tun, deren Funktion darin besteht, $\mathrm{NaCl}$ von der verdünnteren Lösung im Blut zu der konzentrierteren im Harn zu transportieren, so müssen in erster Linie die Plasmamembranen an dieser Stelle für die Ionen des Chlornatriums durchlässig sein. Für den positiven Stromtransport in den Kapillaren könnten also außer den positiven Wasserteilchen und den $\mathrm{H}^{\prime}$-Ionen noch das $\mathrm{Na}$-Ion zur Verfügung stehen. Auf den Verlauf der stenolytischen Wasserzersetzung ist dieser Umstand ohne Einfluß, denn Stromleitung und Elektrodenvorgänge sind voneinander völlig unabhängig. Wandert eine positive Ladung zu, so wird eine positive Ladung entladen, und das trifft, wie wir schon betonten, das am leichtesten $\mathrm{zu}$ entladende lon. Das $\mathrm{Na}$ Ion wird also unberührt bleiben und ein $\mathrm{H}^{\cdot}$-Ion dafür entladen werden. Was geschieht aber in diesem Falle mit dem zugehörigen $\mathrm{Cl}^{\prime}$-Ion? Da es mit sezerniert wird, muß es. gleichfalls durch die Membran treten; beruht die Sekretion auf elektrischer Grundlage, dann muß es einen anderen Weg gehen als das $\mathrm{K} \cdot$-Ion. Es wird dann vom negativen Strom getragen und wenn das K-Ion den Weg durch die Kapillaren nähme, so müßte das $\mathrm{Cl}^{\star}$-Ion durch die Membranteilchen wandern. Unter diesen Verhältnissen würde das Chlornatrium durch den Strom von der negativen Membranseite nach der positiven Seite transportiert werden. Im umgekehrten und wahrscheinlicheren Fall müßten aber umgekehrt die 
negativen $\mathrm{Cl}^{\prime}$-Ionen durch die Kapillaren, die positiven $\mathrm{K}$-Ionen im positiven Strom durch die Membranteilchen getragen werden.

Vergleichen wir nun diese Erklärung mit den Arbeiten die Bethe und Toropoff ${ }^{1}$ ) über den Transport von Ionen durch stromdurchflossene Membranen gemacht haben. Diese Forscher sind von der von Nernst und Riesenfeld theoretisch und experimentell behandelten Erscheinung ausgegangen, daß ein elektrischer Strom, der durch zwei von einer zweiten Phase, wie z. B. Phenol, getrennte Räume hindurchgeht, in dem diese Räume erfüllenden, ursprünglich überall gleichen Elektrolyten, Konzentrationsdifferenzen hervorruft. Diese sind eine Folge der Verschiedenheit die das Verhältnis der lonenwanderungsgeschwindigkeiten in den beiden Phasen annimmt. AeuBerlich ähnliche Erscheinungen wurden nun von den genannten Autoren beim Durchgang des Stroms durch Diaphragmen aus Gelatine, Kollodium, Kohle, Ton usw, konstatiert. B. und T. weisen aber darauf hin, daß man in diesen Fällen nicht gut von zwei Lösungsphasen reden kann; sondern fassen die Diaphragmen, wie bereits erwähnt wurde, als Kapillarensysteme auf; und daß die von ihnen beobachteten Erscheinungen tatsächlich auf kapillarelektrischer Grundlage beruhen, geht daraus hervor, daß der Effekt nach Größe und Richtung von der elektrischen Ladung beeinflußt wird, die die Flüssigkeit der Membran erteilt. Die beobachteten Konzentrationsverschiebungen, die sich auf alle in den Lösungen vorhandenen Ionen erstrecken, werden dadurch erklärt, daß das eine von ihnen, etwa das Kation, in einer Säurelösung an der Wand festgehalten wird, dadurch an Beweglichkeit einbüßt, während das Anion frei durch die Kapillaren hindurchwandert. An den Grenzflächen treten Konzentrationen in dem das Anion durch das Diaphragma hindurchwandert, die Kationen dagegen aus der Flüssigkeit nach der Grenzfläche hin oder von dieser weg, in die Flüssigkeit. Die Reaktion zwischen Kation und Wandsubstanz kann dabei sowohl auf einfacher Oberflächenwirkung als auch auf chemischer Reaktion beruhen.

Die Wandsubstanz wird von B. und T. als isolierend angenommen. Diese Annahme ist als Grenzfall zwecks Aufstellung der Gleichungen berechtigt, praktisch aber dürfte sie wohl nie zutreffen. Wenn die Membranteilchen sich mit Kation beladen," so werden sie auch als Elektrolyten wirken, denn sie werden natürlich das Bestreben haben,

1) A. Bethe u. Th. Torop off, Zeitschr. f. physik. Chem. 88 , $686 \mathrm{ff}$. (1914); 89, 597 ff. (1915). 
in der betreffenden Stromrichtung durch die Wand zu wandern. Auf derartigen Kationen-Beladungen beruht nun der herrschenden Annahme gemäb nicht nur bei lebenden Membranen, sondern auch bei leblosen Diaphragmen das Zustandekommen der Membranpotentiale, z. B. auch an Ferrocyankupferhäutchen. Es ist lange bekannt, daß diese einen auf starker $\mathrm{K}$-Adsorption beruhenden wechselnden $\mathrm{K}$-Gehalt haben und demgemäB konnte $\mathrm{Beutner}$ an ihnen auch die elektrochemische Reversibilltät für $\mathrm{K}$ nachweisen. In einer derartigen Membran werden aber zweifellos die mit diesem Ion beladenen Teilchen im elektrischen Strom durch die Substanz wandern. Wenn nun durch ein solches Diaphragma irgend ein Salz unverändert einseitig transportiert werden soll, so müssen die Kationen ebenso schnell in der Wandsubstanz wandern, wie die Anionen in den Kapillaren. Ist diese Bedingung nicht erfüllt, so wird gleichzeitig mit der einseitigen Erhöhung der Salzkonzentration auch eine einseitige Ansäurung erfolgen.

Wenn wir aber die Sekretions-Erscheinungen, wie es versucht wurde, durch ringförmige Membranströme erklären, so ist hierzu noch eine zweite Annahme nötig. Die Kationen müssen nicht nur durch die Membransubstanz wandern können, es muß vielmehr auberdem unter deren Einfluß ihre Wanderungsgeschwindigkeit in dem Kapillarenwasser stark herabgesetzt sein; sonst würden sie nämlich durch den in den Kapillaren zuruckkehrenden Strom wieder an ihre ursprüngliche Stelle zurückbefördert werden, und es könnte keine einseitige Anhäufung erfolgen. Eine solche Annahme erfordert aber nicht nur die physiologische Theorie, sie liegt viel mehr auch im Sinn der Erklärungen, die Bethe und Toropoff ihren Versuchen geben. Würden nämlich die Kationen nur an der Wandsubstanz, nicht aber auch im Kapillarenwasser beeinflußit werden, dann wäre das Zustandekommen der beschriebenen Effekte gar nicht möglich; es würde sich nämlich ein Gleichgewichtszustand zwischen Oberfläche und Flüssigkeit herstellen, der auf deren absolute Ionen-Konzentration gar keinen merklichen Einfluß haben könnte; und nach dessen Herstellung würden sich die noch übrigen Kationen frei im Kapillarenwasser bewegen, ohne daß sie irgendwie von der im Ionen-Gleichgewicht befindlichen Membran beeinflußst werden könnten.

Die Annahmen, die wir zur elektroosmotischen Erklärung der Sekretion gemacht haben, sind also gar nicht neu, sie stellen vielmehr nur eine Erweiterung der SchluBfolgerungen dar, die Bethe und Toròpoff aus ihren Beobachtungen gezogen haben. Die Fort- 
setzung dieser Untersuchungen an geeigneten Membranen wird zweifellos noch weitere Aufschlüsse liefern.

Entschließt man sich $z u$ diesen Annahmen, so bieten die verschiedenen Komplikationen der Sekretionsprozesse keine weiteren Schwierigkeiten. Wir haben bisher vorausgesetzt, daß $\mathrm{Na}^{\cdot}$ und $\mathrm{Cl}^{\prime}$ ihre verschiedenen Wege mit der gleichen Geschwindigkeit zurücklegen. Ist das nicht der Fall, wandert z. B. $\mathrm{Cl}^{\prime}$ schneller, so werden an Stelle von $\mathrm{Na} \cdot \mathrm{H}$-Ionen treten und das sezernierende Organ kann aus einer neutralen oder gar alkalischen Flüssigkeit ein saures Sekret herstellen, wie es tatsächlich beim Harn der Fall ist. Der Wassergehalt des Sekrets wird davon abhängen, ob und wieviel positiv geladene Wasserteilchen außer den Ionen an der Stromleitung teilnehmen. Diese Verteilung der $z u$ transportierenden Elektrizitätsmenge hängt von der Konzentration und der Wanderungsgeschwindigkeit der Ionen in der Membran, sowie von der elektrischen Beladung des Wassers ab, also von Eigenschaften, die mit der Beschaffenheit der Membransubstanz veränderlich sind und somit der physiologischen Regulierbarkeit unterliegen können. Jedenfalls ist es auf der gegebenen Grundlage leicht, sich klarzumachen, warum das eine Mal konzentriertere, das andere Mal verdünntere Sekrete entstehen, oder wie z. B. durch die Tätigkeit der Darmwand die ganze Lösung, Wasser mitsamt den Salzen, von einer Seite nach der anderen geschafft werden.

Bisher haben wir nur von der Resorption und Sekretion dissoziierter Stoffe geredet; nun sind noch einige Worte über das Verhalten von Nichtelektrolyten zu sagen. Handelt es sich dabei um Kolloide, so werden sie sich, vermöge ihrer lonenbeladung bei der Wanderung genau so verhalten, wie die lonen selbst; höchstens nicht dissoziierte Kristalloide könnten anscheinend Schwierigkeiten bieten. Dazu ist aber zu bemerken, daß es einerseits kaum physiologisch wichtige Stoffe gibt, die nicht, wenn auch in geringem Maße dissoziiert wären; ist doch selbst der Traubenzucker eine allerdings sehr schwache Säure. Vor allem scheint es aber, daß auch kristalloide Substanzen durch den elektrischen Strom überführt werden können;

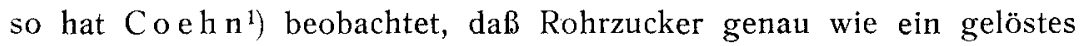
Kolloid zur Elektrode wandert. Das würde bedeuten, daß die Solvatteilchen, Aggregate, die aus Molekülen des gelösten Stoffes und Wasser zusammengesetzt sind, sich gegen das Wasser genau in der gleichen Weise elektrisch laden, wie kolloidale Teilchen. Diese Er-

1) A. Coehn, Zeitschr. f. Elektrochemie 15, 652 (1909). 
scheinung verdient im Interesse der Klärung des Resorptions- und Sekretionsproblems eingehendere Bearbeitung.

c) Die Energietransformation im synthetischen St offwechsel.

Auch im Stoffumsatz gibt es unfreiwillige Vorgänge, Reaktionen die, für sich allein betrachtet, von einem Gleichgewichtszustand wegführen. Auch hier besteht die Notwendigkeit der Verknüpfung mit einem Energie liefernden Prozeß: und auch dafür kommt außer dem Fall der photosyntetischen $\mathrm{CO}_{2}$-Assimilation ausschließlich der abbauende Stoffwechsel in Frage. Wie weit bei dieser Art von Energietransformation der Weg über die elektrische Energie eine Rolle spielt, wollen wir jetzt erörtern ${ }^{1}$ ).

Bei Besprechung dieser Frage kommen wir von selbst dazu, den Stoffwechsel der Pflanze in den Vordergrund zu schieben. Auch abgesehen von der photochemischen Kohlesäurezersetzung spielen hier alle Reduktions- und synthetischen Prozesse eine wesentlich bedeutendere Rolle als im Tierkörper; vor allem treten sie uns reiner als dort entgegen, wo sie oft in unentwirrbarer Weise mit dem Abbaustoffwechsel verknüpft sind. Erscheinungen, wie die Ernährung eines Pilzes der mit Hilfe verschiedenartigster reiner C - Quellen und einiger anorganischer Salze den ganzen Aufbau bestreitet, kommen im tierischen Körper nicht vor. Daß hier trotzdem, unfreiwillige Reaktionen ebenso wohl verlaufen, wie in der Pflanze, z. T. sogar zweifellos in identischer Weise, ist sicher, und so mag das, was hier von der Pflanze zu sagen ist, als Beispiel für den gesamten organischen. Stoffwechsel dienen ${ }^{2}$ ).

Die einfachsten unfreiwilligen Reaktion sind Reduktionsvorgänge, die allenthalben die Synthese begleiten; so z. B., wenn ein Pilz aus Traubenzucker, Nitraten uud anderen anorganischen Salzen seinen Körper aufbaut. Da muß $\mathrm{NO}_{3}$ zur $\mathrm{NH}_{2}$-Gruppe, $\mathrm{SO}_{4}$ zur SH-Gruppe reduziert werden, damit die Bausteine der Eiweißkörper hergestellt werden können. Es liegt selbstveständlich die Annahme nahe, daß

1) Es liegt der Gedanke nahe, mit der kapillarelektrischen Wasserzersetzung auch die photosynthetische $\mathrm{CO}_{2}$-Assimilation in Zusammenhang $\mathrm{zu}$ bringen, besonders in Verbindung mit der von verschiedener Seite vertretenen Theorie der photoelektrischen Natur dieses Vorganges. Ich schiebe die Diskussion dieses Gegenstandes auf, bis mir eine begonnene Experimentaluntersuchung ein sicheres Urteil darïber gestattet.

2) Vgl. E. Abderhalden, Synthese der Zellbausteine in Pflanze und Tier (1912), und die dort genannten Arbeiten dieses Autors und seiner Schüler. 
derartige Reduktionen durch den stenolytisch entstehenden Wasserstoff bewirkt werden; haben wir doch diese Annahme sogar machen müssen, um den Ablauf der anoxybiotischen Atmung zu erklären, wobei gebundener Sauerstoff zur Verbrennung der Atmungsmaterialien dient, wie z. B. bei der Denitrifikation oder der Cannizzaro'schen Umlagerung in den Gärungsprozessen; nur müssen wir uns darüber klar sein, dab wir hiermit zwar eine Schluffolgerung aus unserer Theorie ziehen, aber nichts erklären, was nicht auch ohne sie verständlich wäre: Wir lernten ja schon jene enzymatischen Reduktionsprozesse verschiedener Art kennen, bei denen es sich meist um Oxydation von Aldehyden auf Kosten gewisser Sauerstoffquellen handelt, unter anderem auch von Nitraten.

Ja es mag sogar sein, daß unter Umständen, wenn es sich um sehr kräftige Reduktionen handelt, die rein enzymatischen Prozesse im Protoplasma mehr leisten können, als die Stenolyse; denn bei dieser haben wir ja immer nur mit niederen Wasserstoffdrucken gerechnet, während in gewissen Stoffwechselvorgängen sogar Wasserstoff vom Atmosphärendruck entsteht. Freilich kennen wir eine derartige Wasserstoffentbindung nur aus dem Stoffwechsel mancher Bakterien und sie dürfte stets von der Zersetzung der Ameisensäure herrühren, die wohl allein unter den in Betracht kommenden Stoffwechselprodukten ein so hohes Reduktionspotential besitzt, daß sie unter Entwicklung gasförmigen Wasserstoffs zerfällt. Dieser Vorgang, der auch durch anorganische Katalyse mit Platinmetallen hervorgerufen werden kann ${ }^{1}$ ), erfolgt wahrscheinlich such im Bakterienkörper enzymatisch und dürfte gleichfalls zu den Wirkungen des mehrfach erwähnten Aldehydferments gehören. Ich will an dieser Stelle auf eine entfernte und sehr unwahrscheinliche Möglichkeit, daß auch diese Ameisensäurezersetzung unter Entbindung freien Wasserstoffs in den Kreis der elektrolytischen Zellreaktionen gehört, nicht eingehen. Ich werde später auf das damit zusammenhängende Problem an der Hand experimenteller Ergebnisse zurückkommen. Wir können aber wohl mit Sicherheit annehmen, $\mathrm{da} B$ in der Bildung und enzymatischen Zersetzung der Ameisensäure ein Mittel zur Durchführung kräftiger Reduktionen liegt, das wahrscheinlich auch von höheren Organismen benutzt wird. $\mathrm{DaB}$ wir in derartigen Fällen die Bildung von Wasserstoff nicht beobachten werden, liegt auf der Hand: er muß ja bei der Reduktion verschwinden.

1) G. Bredig u. B la ckadder, Zeitschr. f. physik. Chem. 81, 385 (1912) ; E. B a u r, Ber. d. Deutsch. chem. Ges. 46, 852 (1913). 
Reduktionsprozesse können also mit der Zellelektrolyse verknüpft sein, sie bedürfen aber an sich keiner besonders gearteten energetischen Verbindung mit den Energie liefernden Oxydationsvorgängen: die rein stöchiometrische Verknüpfung durch die Enzyme ist imstande das Nötige zu leisten. Das Gleiche gilt auch für jene komplizierteren Erscheinungen an sich unfreiwilliger Reaktionen, die sich in succesive Oxydationen und Reduktionen auflösen lassen. Wenn z. B. im Tier- oder Pflanzenkörper aus Oxysäuren und Ammoniak Aminosäuren entstehen nach der Gleichung

$$
\text { R. } \mathrm{CHOH} \cdot \mathrm{COOH}+\mathrm{NH}_{3}=\mathrm{R} \cdot \mathrm{CH} \cdot \mathrm{NH}_{2} \cdot \mathrm{COOH}+\mathrm{H}_{2} \mathrm{O}
$$

so ist das keine einfache Deshydratationssynthese, sondern ein komplizierter Vorgang, der ebenso wie der Abbau der Aminosäuren über die entsprechende Ketosäure führt. Es findet also zuerst eine Oxydation statt, der dann eine mit Reduktion verknüpfte Synthese folgt. In dieser zweiten Teilreaktion liegt der Prozeb, der der Verbindung mit einem Energie liefernden Vorgang bedarf. Es ist instruktiv diese Verkettung an einer Reaktionsfolge zu beobachten, die wir außerhalb des Organismus durchführen können. Nach einer von de Jong beschriebenen und von Erlenmeyer näher gedeutenden Reaktion entsteht aus $2 \mathrm{Mol}$. Brenztraubensäure und $1 \mathrm{Mol}$. Ammoniak Azetylalanin, das durch Hydrolyse in Alanin und Essigsäure gespalten werden $k_{a n n^{1}}$ ). Die Summe all dieser Reaktionen läßt sich durch die Gleichung darstellen.

$2 \mathrm{CH}_{3} \cdot \mathrm{CO} \cdot \mathrm{COOH}+\mathrm{NH}_{3}=\mathrm{CH}_{3} \cdot \mathrm{CHNH}_{2} \cdot \mathrm{COOH}+\mathrm{CH}_{3} \cdot \mathrm{COOH}+\mathrm{CO}_{2}$.

Die Reaktion beginnt damit, daß sich 1 Mol. brenztraubensaures Ammonium in die tautomere $\alpha$-Oxaminoproprionsäure umlagert.

$$
\mathrm{CH}_{3} \cdot \mathrm{CO} \cdot \mathrm{COONH} \mathrm{CH}_{4} \rightarrow \mathrm{CH}_{3} \cdot \mathrm{COH} \cdot \mathrm{NH}_{2} \cdot \mathrm{COOH}
$$

Diese Verbindung muß nun, um zum Alanin zu führen, reduziert werden, und in der beschriebenen Reaktionskette erfolgt dies auf dem Umweg über Azetylierung mittels eines zweiten Moleküls Brenztraubensäure. Das Endergebnis ist, daß nach der Hydrolyse des Azetylanalins Alanin entstanden, und das zweite Brenztraubensäure-Molekül zu Essigsäure und Kohlensäure oxydiert worden ist. $\mathrm{Ob}$ auch im Organismus die Aminosäuresynthese stets den komplizierten Weg über die Azetylverbindungen nimmt, oder ob hier eine einfachere Verknüpfung mit einem Oxydationsprozeß möglich ist, ist nur eine

1) Vgl. R. A.H. Plimmer, Die chemische Konstitution der Eiweißkörper (Dresden 1914), S. 83. 
sekundäre Frage. Unter allen Umständen lehrt uns das Beispiel, daß auch für diese Synthese irgend eine besondere Art der Energietransformation nicht nötig ist, sondern $\mathrm{dab}$ sie durch geeignete stöchiometrische Verknüpfung mit Oxydationsprozessen durchgeführt werden kann.

Dieser Fall gibt deswegen zu denken, weil beim Aufbau der wichtigsten Bestandteile des lebenden Organismus, der Eiweißkörper, der Fette und der Polysaccharide Deshydratationssynthesen eine große Rolle spielen, und so liegt die Frage nahe, ob wir berechtigt sind, uns auch diese Prozesse, vor allem wenn sie als unfreiwillige Reaktion verlaufen, in sukzessive Oxydations- und Reduktionsvorgänge aufgelöst zu denken, und so die allereinfachste Verknüpfungsweise mit dem Energie liefernden Atmungsstoffwechsel anzunehmen. Rein formal läßt sich natürlich jede Deshydratation in die zwei genannten Teilreaktionen aufgelöst denken, weil stets einer Gruppe ein $\mathrm{H}-$ Atom, einer anderen ein Hydroxyl entzogen wird. Die Frage ist nur, ob in den konkreten Fällen die Reaktion wirklich diesen Verlauf nimmt oder ob sie ohne Dazwischenkunft von Oxydations- und Reduktionsmitteln als Ganzes vor sich geht. Das Erstere wird in einer ganzen Anzahl von Fällen zutreffen können und namentlich haben wir zu einer solchen Vermutung dann Veranlassung, wenn Deshydrationssynthesen als Elektrodenvorgänge verlaufen $\left.{ }^{1}\right)$. Daß das generell aber nicht nötig ist; lehrt der Vorgang, den wir als das Prototyp solcher Deshydratationssynthesen ansehen können: die Umsetzung zwischen Aethylalkohol und Essigsäure einerseits, Ester und Wasser anderseits nach der Gleichung

$$
\mathrm{CH}_{3} \cdot \mathrm{CH}_{2} \mathrm{OH}+\mathrm{CH}_{3} \cdot \mathrm{COOH} \leftrightarrows \mathrm{CH}_{3} \cdot \mathrm{CO} \cdot \mathrm{C}_{2} \dot{\mathrm{H}}_{5}+\mathrm{H}_{2} \mathrm{O} \text {. }
$$

Diese Reaktion erfolgt bekanntlich in umkehrbarer Weise, sie geht je nach dem Konzentrationsverhältnis der reagierenden Stoffe in der einen oder in dèr anderen Richtung vor sich; entweder wird der Ester hydrolytisch gespalten oder unter Deshydratation aufgebaut, und bei der Synthese reagieren die in Betracht kommenden Moleküle miteinander unter Wasserabgabe ohne Dazwischenkunft von Oxydations- und Reduktionsmitteln.

1) Vgl. die Zusammenstellung solcher Beispiele bei Fr. Fichter, Zeitschr. f. Elektrochemie 24, 41 (1918); der von Fichter selbst studierte Vorgang, die elektrochemische Harnstoffbildung, scheint aber nach seinen Ausführungen eine andere Ursache, zu haben, nämlich die Erwärmung an den Elektrodén. 
Bekanntlich begegnen wir der gleichen Erscheinung auch bei einer Anzahl biologisch wichtiger Reaktionen: eine ganze Reihe von enzymatischen Hydrolysen bleiben ebenso wie die Esterspaltung bei einem bestimmten Gleichgewichtszustand stehen, und läßt man das entsprechende Enzym auf die reine Lösung der Spaltungsprodukte wirken, so erfolgt Deshydratationssynthese. Auf diese Weise hat man die Synthese von Maltose und Isomaltose, von Fetten, Glukosiden und anscheinend auch von Eiweißkörpern aus den Spaltungsprodukten durchgeführt ${ }^{1}$ ).

Diese Tatsache, so fundamental auch ihre Bedeutung ist, genügt jedoch nicht, um den Verlauf der in Betracht kommenden Synthesen im Organismus restlos aufzuklären. Erstens ist man in manchen wichtigen Fällen, z.B. beim Rohrzucker und der Stärke, mit den feinsten anwendbaren Methoden nicht imstande, das Stehenbleiben der Hydrolyse bei einem Gleichgewichtszustand und die Umkehrung der Reaktion bei Anwendung der reinen Spaltungsprodukte festzustellen. Es erfolgt also in diesen Fällen in wässeriger Lösung überhaupt keine nachweisbare Synthese, und auch dort wo sie, wie in den oben genannten Beispielen tatsächlich vor sich geht, ist der Gleichgewichtszustand sehr stark nach der Seite der Hydrolysenprodukte verschoben; es findet also außerhalb des Organismus weitgehender Abbau der Stoffe statt, deren Synthese wir im aufbauenden Stoffwechsel glațt vor sich gehen sehen.

Bei der Beurteilung dieser Vorgänge ist es nun in erster Linie nötig, zu beachten, daß sie im lebenden Protoplasma nicht in Wasser, sondern in einem Medium von wesentlich anderen Eigenschaften vor sich gehen, und das ist durchaus nicht ohne Einfluß auf die Gleichgewichts lage der Reaktion. lch habe früher ${ }^{2}$ ) zur Erläuterung dieses Einflusses vant' $\mathrm{H}$ off's Ableitung über die Verschiebung des chemischen Gleichgewichts durch das Lösungsmittel herangezogen. Sie beruht auf der Ueberlegung, daß, wenn in zwei unmischbaren Phasen die gleiche Reaktion vor sich geht, in beiden chemisches Gleichgewicht herrschen muß, sobald das Verteilungsgleichgewicht inbezug auf die reagierenden Stoffe hergestellt ist. Da dieses aber wiederum von der Löslichkeit der einzelnen Substanzen abhängt, indem sich bei der Verteilung eine jede von ihnen in dem Lösungsmittel anhäuft, in dem sie leichter

1) Vgl. die Zusammenstellung bei R. H ö be r, Physik. Chem. usw., S. 666 ff.; E. Abderhalden, Fermentforschung Nr. 1, $57 \mathrm{ff}$. (1914).

2) A. Nathansohn, Stoffwechsel der Pflanzen, S. 437 ff. 
löslich ist, so folgt daraus, daß auch das chemische Gleichgewicht. von der Löslichkeit beeinflußt werden muß, und in jeder Phase zu Gunsten des Stoffes verschoben ist, der sich leichter in ihr löst. In Anbetracht der im Protopiasma herrschenden Bedingungen ist es richtiger, nicht das Lösungs-, sondern das Adsorptionsvermögen der Reaktionsmedien heranzuziehen. Das kommt aber im Prinzip auf das Gleiche hinaus. Gibbs hat aus seinem Theorem über den Einflub gclöster Stoffe auf die Oberflächenspannung bereits die SchluBfolgerung gezogen, daß auf jeder Oberfläche die Bildung derjenigen Reaktionsprodukte begünstigt sein wird, die die Spannung herabsetzen; das sind aber die, die sich an ihr ansammeln. Es handelt sich hier, wie leicht ersichtlich, um das gleiche Prinzip wie in van't' Hoff's $\mathrm{Ab}$ leitung über den Einfluß des Lösungsmittels; nur tritt anstelle der Verteilung zwischen $z$ wei Phasen diejenige zwischen der Flüssigkeit und ihrer Oberfläche.

In einer Plasmastruktur, aiso einem Oberflächensystem, wird demnach stets die Bildung derjenigen Stoffe begünstigt sein, die besonders stark adsorbiert werden, und während $z$. B. in wässeriger Lösung das Gleichgewicht Rohrzucker - Invertzucker soweit auf der Seite des letzteren liegt, daß wir vom Rohrzucker nach vollendeter Hydrolyse nichts mehr nachweisen können, würde auf einer Plasmaoberfläche, die sehr starkes Adsorptionsvermögen für Rohrzucker, verschwindend kleines für Invertzucker hätte, ohne weiteres enzymatische Synthese des Dissaccharids stattfinden können. Daß dieses Prinzip für den Stoffwechsel, und vor allem für die Synthesen im lebenden Protoplasma von großer Bedeutung ist, scheint mir außer Zweifel; jedoch genügt es nicht zur Aufklärung aller Erscheinungen, die dabei $\mathrm{zu}$ beobachten sind.

In Pflanzenzellen haben z. B. Chloroplasten und Leukoplasten die Fähigkeit, aus zugeführtem Traubenzucker unter Deshydratation Stärke zu bilden. Dieser Vorgang, der in wässeriger Lösung freiwillig erfolgenden Reaktion entgegengesetzt, kann an und für sich auf den plasmatischen Strukturoberflächen der Stärkebildner rein katalytisch vor sich gehen, wenn sie nur ein besonders starkes Adsorptionsvermögen für Stärkemoleküle haben. Aber in Wirklichkeit verbleibt doch die Stärke nicht auf diesen Oberflächen, sie tritt vielmehr in ungelöstem Zustande auf, und so kann der Stärkebildner theoretisch unbegrenzte Mengen von Traubenzucker in Stärke überführen und dauernd ausscheiden. Tatsächlich übertrifft sehr häufig das Volum der entstehenden Stärkekörner das der plasmatischen Stärkebildner um ein Vielfaches. Prinzpiell gilt das Gleiche, wenn ein Pilz 
Zucker zum Aufbau der aus dem Protoplasma ausgeschiedenen Zellutosewand verwendet, wenn der vom Plasma aus Invertzucker hergestellte Rohrzucker im Zellsaft erscheint, wenn Fett in Gestalt von Tröpfchen, oder Eiweiß in Form von Aleuronkörpern oder Dotterplättchen im Protoplasma ausgeschieden wird. In all diesen Fällen erscheinen die synthetisch erzeugten Produkte außerhalb der lebenden Substanz, also an Orten, an denen sie sich freiwillig in die Materialien, die zu ihrem Aufbau dienten, wieder zersetzen können. An einem Punkte der Reaktionskette, die mit dieser Ablagerung endet, muB also ein unfreiwilliger Prozeb erfolgt sein, bei dem Arbeit geleistet wurde und der demnach auf irgend einer Weise mit einem Energie liefernden Vorgang verknüpft war.

Damit sind wir zum Ausgangspunkte unserer Frage zurückgekehrt: ob bei dem unfreiwilligen Verlauf der Deshydratationssynthese von Eiweiß, Fett und Polysacchariden Reduktionsvorgänge die notwendige Verbindung mit den Energie liefernden Atmungsstoffwechsels herstellen. Auf Grund unserer bisherigen Betrachtungen können wir bereits sagen; daß die Vorstellung von der Zerlegung dieser Synthesen in Oxydationsund Reduktionsvorgängen auf ein prinzipielles Bedenken stößt: die „unfreiwillige“ Deshydratation würde, wenn sie in dieser Weise verliefe, auf ganz anderem Wege erfolgen, ais die entsprechend freiwillige enzymatische Reaktion, und die synthetische Wirkung der Enzyme wäre bei den eigentlichen organischen Synthesen völlig ausgeschaltet.

Anknüpfungspunkte für eine nähere Diskussion der vorliegenden Möglichkeiten bieten uns die Erfahrungen über die Synthese der Polypeptide. Bekanntlich sind dies Stoffe, in deren Molekül Aminosäuren in gleicher Weise verkettet sind, wie in den Eiweißkörpern, die also nichts anderes darstellen, als Polypeptide von sehr komplexer Zusammensetzung und großem Molekulargewicht. Die Synthese einfacher Körper dieser Gruppe, die wir jetzt ins Auge fassen wollen, ist also der erste Schritt, der auch im Protoplasma beim Aufbau der Eiweibkörper getan werden muß.

Ein Teil der dafür in Betracht kommenden Methoden führt über die Säurechloride der Aminosäuren, von denen sich ein Molekül mit einem unveränderten Aminosäuremolekül unter $\mathrm{HCl}$-Abscheidung zum Peptid verkettet:

R. $\mathrm{CHNH}_{2} \cdot \mathrm{COCl}+\mathrm{R} \cdot \mathrm{CHNH}_{2} \cdot \mathrm{COOH}=\mathrm{R} \cdot \mathrm{CHNH}_{2} \cdot \mathrm{CO} \cdot \mathrm{NH}_{-}^{-} \mathrm{COOH}$. R. Zum Säurechlorid gelangt man aber von der Aminosäure durch Einwirkung von Phosphorpentachlorid, also einem Körper von starkem 
Reaktionsvermögen, wie er für die Reaktionen im Organismus nicht in Frage kommt. Hier würden aus den Aminosäuren durch Reduktion nur die entsprechenden Aminoaldehyde entstehen ${ }^{1}$ ). Tatsächlich hat $\mathrm{Pauly^{2 }}$ ) die Vermutung ausgesprochen, daß die Eiweißsynthese im Organismus über die Aminoaldehyde geht, die ihrerseits aus den Aminosäuren durch Reduktion entstehen müßten. Sie sollen mit den Aminosäuren sich zu Verbindungen nach Art der Schiff'schen Basen kondensieren, und das Kondensationsprodukt müßte an der Bindungsstelle einem Oxydationsprozesse unterliegen. Diese Vorstellung würde allerdings den Vorzug haben, die Verbindung der synthetischen Reaktion mit dem Atmungsstoffwechsel in sehr einfacher Weise zu erklären. Solange aber der Beweis dafür nicht vorliegt, müssen wir auch noch eine andere Möglichkeit ins Auge fassen, auf die wir gleichfalls durch eine Methode der Peptidsynthese hingewiesen werden ${ }^{3}$ ).

Man gelangt zu Peptiden nämlich auch durch Hydrolyse der Diketopiperazine, die durch Vereinigung je zweier anhydrierter Aminosäuremoleküle entstehen, z. B.

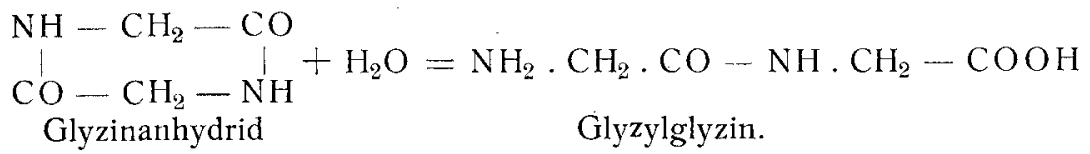

Zum Glyzinanhydrid kommen wir leicht vom Glykokollester $\mathrm{CH}_{2} \mathrm{NH}_{2}$ $\mathrm{COO} . \mathrm{C}_{2} \mathrm{H}_{5}$, der beim Erhitzen Alkohol abspaltet und in das Anhydrid übergeht. Für unsere Betrachtung ist nun springender Punkt die Frage, in welcher Weise wir vom Glyzin zum Ester gelangen. Das erfolgt im Prinzip auf Grund der zu einem Gleichgewicht führenden Reaktion, die wir früher für den Essigsäureaetylester erwähnt haben. Um aber den Prozeß quantitativ durchzuführen, läßt man ihn in alkoholischer Lösung vor sich gehen und sorgt dafür, daß das durch die Reaktion erzeugte Wasser dauernd durch einen Strom von Alkoholdämpfen entfernt wird. Dadurch gelingt es, die Reaktion, die sonst auf einer sehr bald erreichten Gleichgewichtsstufe stehen bleiben würde, quantitativ durchzuführen, und damit ist das Material gegeben, aus dem sich dann das Dipeptid freiwillig aufbaut. Das gleiche Prinzip, Vornahme der Reaktion im wasserfreien Medium und Entfernung des bei der

1) Daß diese Reaktion möglich ist, hat C. Neuberg gezeigt. Ber.d. Deutsch. chem. Ges. 41, 2085 (1908).

2) H. Pauly, Zeitschr. f. physiol. Chem. 99, 161 (1916).

3) Vgl. dazu die negativen Ergebnisse von E. Abderhalden und $H$. Spinner, Zeitschr. f. physiol. Chem. 106, 309 (1919). 
Reaktion entstehenden Wassers, kommt auch für die künstliche Synthese anderer physiologisch wichtiger esterartiger Verbindungen in Frage, z. B. von Säureamiden aus den entsprechenden Ammoniaksalzen und Fetten aus Fettsäure und Glyzerin. Während in Wasser die Verseifung dieser Stoffe in weitgehendem Maße vor sich geht, kann man ihre Synthese durchführen, wenn man z. B. von den wasserfreien Ammoniaksalzen, resp. von dem entsprechenden Gemisch von Fettsäure und Glyzerin ausgeht, und durch Abdestillation das entstehende Wasser entfernt.

Diese Erzwingung einer einseitig gerichteten Reaktion durch dauernde Störung des Gleichgewichtszustandes ist nun ein Prinzip, das zur Erklärung der Synthesen im Organismus geeignet erscheint. Zwar ist es undenkbar, daß hier bei der synthetischen Bildung von Petten, Polysacchariden und Eiweißstoffen dauernd das Wasser entfernt wird, wie in den beschriebenen rein chemischen Synthesen; das ist selbstverständlich in wasserdurchtränkten Protoplasmakörpern schlechthin unmöglich. Aber die dauernde Entfernung des anderen Reaktionsproduktes, etwa des entstehenden Disacchararids, würde genau dasselbe leisten; auch auf diesem Wege ließe sich die Reaktion, die an und für sich mehr oder weniger bald stehen bliebe, zu Ende führen. Die Durchführung des Prozesses könnte, wie oben auseinandergesetzt wurde, durch selektives Adsorptionsvermögen der tätigen Plasmaschichten für die zu erzeugende Substanz gefördert werden. Die Entfernung des Reaktionsproduktes müßte aber unter Arbeitsleistung geschehen, denn wenn das chemische Gleichgewicht erreicht ist, dann herrscht auch, wie ausdrücklich betont worden ist, zwischen dem Ort der Reaktion und seiner Umgebung Diffusionsund Adsorptionsgleichgewicht, das nur durch einen aktiven sekretorischen Prozeß gestört werden kann.

Nach dieser Betrachtungsweise würde die Arbeitsleistung bei chemischen Synthesen und die dazu.nötige Verknüpfung mit dem Energie liefernden Atmungsstoffwechsel auf der gleichen Basis stehen, wie die der sekretorischen Arbeitsleistung, und in letzter Linie wäre auch hier Elektrodiffusion das zur. Energietransformation verwendete Mittel. Dieses Prinzip ist auf alle synthetischen Prozesse anwendbar, denn, theoretisch führt jede Reaktion zu einem Gleichgewicht, mag es auch noch so sehr nach der einen Seite hin verschoben sein. Es erklärt aber ohne weiteres auch eine andere Erscheinung, einen ganz wesentlichen Unterschied zwischen der organischen Synthese in vitro und im Organismus: Obwohl in diesem letzteren die Mittel zur 
Durchführung chemischer Arbeit bedeutend beschränkter und weniger mannigfaltig sind als im Laboratorium, arbeiten sie doch weit vollkommener. Sie verlaufen, wie schon Emil Fischeri) betont hat, viel glatter, als die „chemischen Methoden, deren sehr geringe Ergiebigkeit bei den üblichen Vergleichen meist vernachlässigt" wird“. Diese einseitige Durchführung der Synthesen im Protoplasma erklärt sich ohne weiteres auf Grund der entwickelten Prinzipien, denn von all den nebeneinander möglichen Reaktionen wird eben nur die eine durchgeführt, die durch Wegschaffung ihres Endproduktes dauernd im Gang erhalten bleibt. Auch asymmetrische Synthesen können auf diese Weise zustande kommen, indem infolge der Asymmetrie der dabei in Funktion tretenden Plasmateilchen asymmetrische Auswahl der Stoffwechselprodukte erfolgt.

$\mathrm{Zu}$ der gleichen Auffassung über den Mechanismus und die Energetik der unfreiwilligen Reaktionen gelangen wir, wenn wir nicht wie bisher von der rein chemischen Seite des Problems ausgehen, sondern von der physiologischen, und zwar von der Betrachtung des Zusammenhanges zwischen Stoffumsatz und Sekretions- und Resorptionsvorgängen. Diese Beziehung muß notwendigerweise immer bestehen, und begegnet uns in ihrer einfachsten Gestalt in der Speicherung von Anilinfarben durch die lebende Pflanzenzelle, die von Pfeffe ${ }^{2}$ ) zuerst studiert und als Vorbild analoger Zusammenhänge im normalen Stoffwechsel des Protoplasmas erkannt wurde. Diese Erscheinung besteht darin, daß in Lösungen gewisser Farbstoffe, wie z. B. Methylenblau der wäBrige Zellsaft lebender Zellen eine Färbung annimmt, die die der Außenflüssigkeit um ein Vielfaches an Intensität übertrifft. Es erweckt den Eindruck, als würde der Farbstoff gegen das Diffusionsgleichgewicht in die Zelle transportiert. Das ist aber nicht der Fall. Er unterliegt vielmehr in ihr der chemischen Bindung durch gewisse Bestandteile des Zellsaftes, so daß jede in die Zelle eindringende Menge sofort beschlagnahmt wird und so dauernd die Möglichkeit für den Eintritt weiterer Farbstoffteilchen entsteht. Dieser doppelte Vorgang, Endosmose und chemische Bindung dauert so lange an, als im Zellsaft noch Stoffe vorhanden sind, die sich mit dem Methylenblau zu einer gefärbten, nicht exosmierenden Verbindung vereinigen.

Es gehen also hier ein Stoffwechsel- und ein Resorptionsvorgang Hand in Hand, ohne daß man sagen könnte, was Ursache und was

1) Emil Fischer, Organische Synthese und Biologie (Berlin 1912), S. 7.

2) W. Pf e ffer, Unters. a. d. botan. Institut Tübingen 2 (1886). 
Wirkung ist; es streben vielmehr zwei miteinander gekoppelte Prozesse einem gemeinsamen Gleichgewichtspunkte $z \mathfrak{u}$, den sie in diesem Falle auch erreichen. Diese Gemeinsamkeit der Gleichgewichtslage von chemischen Reaktionen und Diffusionsvorgängen, an denen die gleichen Stoffe beteiligt sind, ist, wie wir gesehen haben, in heterogenen Systemen stets vorhanden. Daraus ergibt sich aber von selbst die weitere Schlußfolgerung, daß Sekretionsvorgänge, die bestehende Diffusionsgleichgewichte stören, notwendigerweise auch in den Stoffwechsel eingreifen müssen. Wir können uns das am Beispiel der Harnstoffsekretion klar machen, bei der die Niere Harnstoff gegen das Diffusionsgleichgewicht transportiert, und so durch aktive Tätigkeit dessen Konzentration im Blute auf einem niedrigen Niveau erhält. Dadurch greift sie aber notwendigerweise fördernd in den chemischen Prozeb der Harnstoffbildung, der an ganz anderer Stelle, wahrscheinlich in der Leber erfolgt, und sie leistet demnach nicht nur osmotische sondern dadurch indirekt auch einen Teil der chemischen Arbeit, die zur ununterbrochenen Durchführung der Harnstoffsynthese notwendig ist. Denken wir uns dieses ganze Organsystem, bestehend aus Leber, Blut und Niere, in eine Zelle zusammengedrängt, so gelangen wir zu dem gleichen Bild, wie vorhin auf Grund der rein chemischen Betrachtungsweise.

Es ist nun nicht $z a$ bezweifeln, daß sich $z$ wischen Protoplasma und Vakuolen dauernd ähnliche Resorptions- und Sekretionsprozesse abspielen, wie zwischen den Drüsenzellen und ihrem Außenmedium, also dem Blut; nur können wir nicht in jedem Falle mit Sicherheit feststellen, wann zur Erklärung jener Wechselwirkungen die Diffusion genügt, und wann nicht. Wenn in einer Pflanzenzelle sich die Vakuolen allmählich durch Vermehrung ihres Eiweißgehaltes in Proteinkörper umwandeln, oder wenn in tierischen Drüsenzellen die auszuscheidenden Sekrete sich zunächst in Granulis ansammeln, so ist natürlich nicht zu entscheiden, ob dies durch reine Diffusion geschieht, oder ob aktive Transportarbeit dabei geleistet wird, die in der beschriebenen Weise auch die für die chemische Leistung der Sekretbereitung notwendige Arbeiten liefern würde. Besonders nahe liegt diese Annahme eines richtenden Einflusses der Plasmatätigkeit, ohne gerade zwingend zu sein, dann, wenn im Innern ein und derselben Zelle zwei verschiedene Sekrete ausgeschieden werden, wie z. B. in den Muskelepitelzellen aus dem Peritoneum von Owenia, in welchen gleichzeitig Eiweißgranula und Uratkonkremente entstehen. ${ }^{1}$ )

1) Vgl. A. Gurwitz, Morphologie und Biologie der Zelle (Jena 1904), S. 169. 
Die enge Beziehung zwischen Stoffumsatz und Sekretion stellt auch Biedermann') in den Vordergrund, wenn er betont, daß zwischen Glykogenbildung und dessen Abscheidung in der Zelle und der extrazellularen Absonderung spezifischer Stoffwechselprodukte, wie Gallenfarbstoffen und Gallensäuren, kein prinzipieller Unterschied besteht. Es erscheint demnach schon von vornherein wahrscheinlich, daß in beiden Fällen, wo es nötig ist, die gleiche Art von aktiver Triebkraft, nach unserer Auffassung also die Elektrodiffusion, eingreift; und aus der Fortführung dieser Betrachtung ergibt sich noch ein Zusammenhang mit einer dritten fundamentalen Funktion: der Formbildung. Deren Beziehung zur Sekretion hat Biedermann an Hand der Darstellung der Bildungsweise geformter Sekrete wiederholt betont. Dazu werden intrazelluläre Ausscheidungen, wie Stärkekörner, ebenso gerechnet wie extrazelluläre Zellmembranen, Chitinhüllen, Kalkschalen usw.; rein chemische und formative Prozesse gehen dabei Hand in Hand. Die letzteren sind naturgemäß sehr kompliziert und der vollständigen Analyse noch nicht zugänglich. Aber dabei tritt ein Moment als wichtiger Faktor allenthalben in den Vordergrund; das ist die Lokalisierung der Absonderungen, die am augenfälligsten dann hervortritt, wenn diese sich auf einen Teil der Zelloberfläche beschränkt, etwa auf die nach außen gerichtete Seite oder auf die Berührungsflächen der sezernierenden Zellen. Es läßt sich zwar keineswegs mit Sicherheit behaupten, daß dieser Lokalisierung ein erzwungener Diffusionsstrom zugrunde liegt. Das Phänomen ist natürlich hier nicht in dem Maße der Untersuchung zugänglich, wie der sekretorische Transport des Harnstoffs aus dem Blute in den Harn, wo wir die Konzentrationen am Ausgangs- und am Endpunkte des Vorgangs vergleichen können. Es liegt aber nahe, anzunehmen, daß wo richtende Kräfte bei der Sekretion eine Rolle spielen, sie überall auf der gleichen Basis ruhen, und unter dieser Voraussetzung würden wir die sekretorische Triebkraft, also die Elektrodiffusion, auch in die organischen Gestaltungsprozesse eingreifen sehen. Daß aber damit die Struktur- und Formprobleme der geformten Sekrete, die Bied ermann aus der vergleichenden Betrachtung der Fülle mannigfaltiger und verwickelter Erscheinungen ableitet, sich nicht erschöpfen lassen, sei ausdrücklich betont. Wir werden in den Schlußbetrachtungen noch einmal darauf zurückommen.

1) W. Bi ederm an n, Pflüger's Arch. 167, 1 ff. (1917). 
d) Die Energietransformation bei den mechanischen Arbeitsleistungen.

Wir sind bei der Analyse der chemischen Arbeitsleistung zunächst auf eine spezifische Verknüpfungsweise zwischen der Atmung als Energiequelle und den von ihr unterhaltenen Reaktionen gestoßen!: der stöchiometrischen Verbindung mit Hilfe von Enzymen. Wir haben aber gesehen, daß auch die unter Arbeitsaufwand erfolgende Verschiebung von Stoffen in dieses Getriebe eingreift. Auf ganz analoge Zusammenhänge treffen wir auch bei den mechanischen Arbeitsleistungen.

Die besondere Transformationsweise der chemischen Energie liegt hier in der Schaffung von Potentialen der Oberflächen- und Volumenergie durch Störung von osmotischen, Oberflächenspannungs- und Quellungsgleichgewichten. Rein thermodynamisch betrachtet liegt hier der energetische Zusammenhang zwischen chemischer Kraftquelle und mechanischer Arbeitsleistung sehr einfach. Für die die auffälligsten Bewegungen am Pflanzenkörper beherrschenden osmotischen Potentiale habe ich bereits bei früherer Gelegenheit diese Beziehung ausführlich entwickelt ${ }^{1}$ ). Kurz gesagt, läuft sie darauf hinaus, daß, wenn z. B. durch Hydrolyse von Stärke Traubenzucker entsteht, die Wärmetönung verschieden ist, je nachdem das Reaktionsprodukt sich anhäuft und so ein Diffusionspotential schafft, oder sich sofort in einer unendlich groß gedachten Wassermenge verteilt, so daß keine örtlichen Konzentrationsdifferenzen zustande kommen. Im ersteren Falle würde die Verbrennung selbst, abgesehen von den dabei vor sich gehenden Diffusionserscheinungen, weniger Wärme liefern als im zweiten, und die Differenz würde der Arbeitsmenge entsprechen, die durch das neu geschaffene Volumenenergie-Potential geleistet werden kann. Analoge Erwägungen hat $\mathrm{Ba} \cdot \mathrm{r}^{2}$ ) auf die Oberflächenspannungstheorie der Muskelkraft angewandt; er legt dar, daß, wenn Erhöhung der Spannung durch Verbrennung einer Substanz auf einer Oberfläche erfolgt, ein Teil der dabei frei werdenden Energie direkt zur Erzeugung des Oberflächenpotentials Verwendung findet. Demgemäß muß auch in diesem Fall die Wärmetönung geringer sein; die Differenz würde bei Verwandlung der potentiellen Energie in lebende Kraft wieder zutage treten.

Osmotische Energiepotentiale spielen, wie Pfeffer $r^{3}$ ) gezeigt hat, die Hauptrolle bei mechanischer Arbeitsleistung durch wachsende

1) A. Nathan sohn, Stoffwechsel der Pflanzen, S. $416 \mathrm{ff}$.

2) E. B a ur, Vierteljahrsschr. d. Naturf.-Ges. Zürich 61, 215 (1916).

3) W. Pfeffer, Druck und Arbeitsleistung durch wachsende Pflanzen. Abh. d. K. S. Ges. d. Wiss. Math.-phys. K1. 33 (1893). 
Pflanzen. Während des Wachstums ohne wesentlichen äuBeren Widerstand sind die Zellmembranen durch den bedeutenden osmotischen Druck des Zellsaftes elastisch gedehnt; muß aber beim Wachstum Arbeit geleistet werden, so wird durch einen aktiven Bildungsprozeß die Zellwand entspannt und der osmotische Druck, über dessen energetischen Ursprung wir uns ja klar sind, wirkt nach außen.

Verwickelter und nicht ganz durchsichtig liegen die Verhältnisse bei den sogenannten Variationsbewegungen der Pflanzen, jenen Bewegungsvorgängen, die teils autonom, d. h. aus inneren Ursachen, teils infolge photischer, chemischer, thermischer oder mechanischer Reize ausgeführt werden und die auf reversiblen, unter "Wasseraustritt erfolgenden Volumänderungen der Zellen beruhen. Die bei diesen Bewegungen in Aktion tretenden Druckkräfte sind bedeutend, sie betragen nach Pfeffers Messungen ca. 3 Atm., und ihre Existenz hat bekanntlich zur Entdeckung des hohen osmotischen Druckes kristalloider Stoffe geführt. Damit hat Pfeffer den Boden für die physikalische Erklärung der Variationsbewegungen geschaffen; sie beruhen auf Schwankungen des osmotischen Druckes, denen der Zellsaft periodisch oder auf Veranlassung äuberer Reize unterliegt.

Das Zustandekommen dieser Druckschwankungen ist nicht völlig aufgeklärt. Es kann erstens auf chemischen Reaktionen beruhen, die den osmotischen Druck des Zellsaftes ändern; die Kontraktion würde durch dessen Herabsetzung, die Ausdehnung durch Erhöhung zustande kommen. Hier sind wiederum zwei Möglichkeiten gegeben; entwedcr bewegen sich diese chemischen Veränderungen im Kreis, indem in jeder der zwei Phasen die Reaktion der vorigen rückgängig gemacht wird, etwa durch abwechselnde Polymerisation und Spaltung bestimmter Moleküle; oder aber der ganze ProzeB bewegt sich in einer Richtung, aber in zwei Abschnitten; im ersten, etwa der Hydrolyse eines Polysaccharides, würde der osmotische Druck erhöht; im zweiten, der Verbrennung des so entstandenen Traubenzuckers zu Kohlensäure, die die Zelle ungehindert verläßt, herabgesetzt. Die energetischen Beziehungen zum Gesamtstoffwechsel sind nach den Erörterungen des vorigen Abschnittes für beide Fälle klar. Im ersteren haben wir es sicher mit einem in einer der beiden entgegengesetzten Phasen unfreiwillig verlaufenden Prozeß $z u$ tun, der in der im vorigen Abschnitt dargelegten Weise mit der Atmung zusammhängen muß. Fällt diese erzwungene Reaktion mit der Druckerhöhung zusammen, so ist der notwendige Arbeitsaufwand größer, als es ohne sie der Fall wäre, und zwar um so viel, als es zur Schaffung des arbeitsfähigen Poten- 
tials bedarf. Erfolgt aber die Druckerhöhung durch die freiwillig erfolgende Reaktionsstufe, so wird dabei ein entsprechend geringerer Betrag frei, als in der entgegengesetzten Phase an Arbeit aufgewendet werden mußte. Erfolgt dagegen der ganze beide Phasen der Bewegung umfassende Reaktionskomplex freiwillig, so wird dabei die chemische Arbeit verwertet, die zu irgend einer Zeit und an irgend einem Orte zum $Z_{w e c k}$ der Herstellung der reaktionsfähigen Substanz aufgewendet wurde, und dafür gelten die allgemeinen Beziehungen zwischen Atmung und chemischer Arbeit.

Es ist aber aus zwei Gründen wahrscheinlich, daß die Variationsbewegungen nicht durch druckändernde Reaktionen, sondern durch Permeabilitätsänderungen der Plasmahaut bewirkt werden. Die chemische Reaktion zur Ausführung der Variationsbewegungen müßte nämlich sehr plötzlich, gewissermaßen explosiv erfolgen, wenn z. B. ein Mimosablatt auf eine leichte Berührung hin eine rasche Senkung ausführt. Das wäre an und für sich noch nichts besonderes, und in der Physiologie des Muskels spielen solche plötzlichen Reaktionen zweifellos die entscheidende Rolle; aber in den in Betracht kommenden Pflanzenzellen sind die Bedingungen dafür so ungünstig wie möglich. Die Plasmaschicht, die doch den Sitz der Reaktion bildet, ist sehr dünn, und im Vergleich dazi der Zellsaftraum, in dem die Reaktionsprodukte zur Wirkung kommen, außerordentlich groß. Es müßte also nicht nur explosive Reaktion, sondern auch sehr rasche Diffusion und gleichmäßige Verteilung der Produkte erfolgen, was nicht recht wahrscheinlich ist. Dazu kommt aber, daß sowohl bei Pflanzenzellen im allgemeinen, als bei den Elementen der Bewegungsgelenke im besonderen durch Beleuchtungswechsel Permeabilitätserhöhung für gewisse Stoffe hervorgerufen wird ${ }^{1}$ ). Beleuchtungswechsel gehört aber $z u$ dénjenigen Reizen, die in zahlreichen Fällen Variationsbewegungen hervorrufen. Die Kontraktion würde also durch eine Permeabilitätserhöhung bewirkt werden können, die zur Exosmose gewisser, am Zustandekommen des osmotischen Druckes beteiligter Stoffe führt. Soweit bietet das Verständnis der Erscheinung keine Schwierigkeiten. Sie beginnen aber bei der Betrachtung der Restitutionsphase. Diese beruht unter allen Umständen auf Wiedererhöhung des osmotischen Druckes; das kann aber kaum anders erfolgen, als dadurch, daß die Zellen die exosmierten Stoffe wieder aufnehmen und dann für sie impermeabel werden. DaB

1) W. W. Lepeschkin, Ber. d. Deutsch. bot. Ges. 26a (1908); Beih. botan. Ztrbl. 24 [I], 308 (1910); A. Tröndle, Jahrb. f. wiss. Bot. 48, 171 (1910). 
zuerst die Impermeabilität wieder hergestellt wird und dann der Stoffwechsel die exosmierten Stoffe ersetzt, ist höchst unwahrscheinlich, denn das würde zu einer Stoffanhäufung in den Zellwänden außerhalb des Protoplasmas führen, die besonders dann ansehnlich werden müßte, wenn wie z. B. im bekannten Fall von Hedysarum gyrans die Variationsbewegungen dauernd und thit beträchtlicher Schnelligkeit ausgeführt werden. Die Anhäufung der exosmierten Produkte müßte hier zur baldigen Sistierung des ganzen Vorganges führen.

Erfolgt aber Wiederaufnahme der exosmierten Stoffe, so kann das nur unter Arbeitsleistung geschehen, wenn sie in der ersten Phase freiwillig aus der Zelle ausgetreten sind, und dann geht die Restitution der Reaktionsfähigkeit durch einen Vorgang vor sich, dessen Mechanik und Energetik mit der der Resorptionsvorgänge identisch ist. An dieser Stelle würden also elektrisch betriebene Diffusionsprozesse in den Vorgang der mechanischen Arbeitsleistung eingreifen. Bernstein hat (loc. cit. $144 \mathrm{ff}$.) versucht, die elektroosmotischen Prozesse direkt zur Erklärung der Variationsbewegungen heranzuziehen. Er stützt sich dabei auf die Tatsache, daß genau wie an tierischen Organen auch an den reizbaren Pflanzenteilen eine negative Schwankung des Oberflächenpotentials an der reagierenden Stelle der eigentlichen Bewegung vorausgeht: Diese Schwankung soll Wasseraustritt, die Wiederherstellung der ursprünglichen Spannung Wasseraufnahme der Zellen hervorrufen. Dem ist das prinzipielle Bedenken entgegenzuhalten, daß die Möglichkeit der Erzeugung des zur Ausdehnung nötigen Druckes von $3 \mathrm{Atm}$. in lebenden Zellen durch Elektroosmose weder experimentell bewiesen, noch wie oben ausführlich dargelegt wurde, theoretisch wahrscheinlich ist; während im Gegenteil für die Erzeugung osmotischen Druckes in dieser Höhe die physikalischen und physiologischen Bedingungen nachweislich vorliegen.

Wir müssen noch schlieflich auf die Frage zu sprechen kommen, welche Rolle bei den Bewegungen rein plasmatischer Gebilde den elektroosmotischen Kräften zuzuschreiben ist. Ich bemerke von vornherein, daß diese Diskussion zu keinem allgemeinen Ergebnis führt, kann aber nicht umhin, den Gegenstand wenigstens in aller Kürze zu berühren. Möglicherweise ist dabei auch mangels eigener Erfahrungen auf diesem Gebiet die Rolle der Elektroosmose in diesen Fällen unterschätzt.

Nur für die Kernteilung hat Bernstein eine auf elektroosmotischer Grundlage beruhende Erklärung entwickelt, die, wenn sie sich auch nicht beweisen läßt, doch wie mir scheint, den physikalischen und physiologischen Tatsachen besser gerecht wird, als andere Theorien. 
Sie läuft darauf hinaus, daß die Bewegungen der Kernfäden auf Lokalströmen beruhen, die zwischen den Zentrosomen einerseits und der Aequatorialplatte andererseits kreisen. Hinsichtlich der Einzelheiten verweise ich auf die Darstellung Bernstein's in seiner Elektrobiologie auf Seite 187-196. Was nun die Plasmabewegungen im allgemeinen, die rotierenden, zirkulierenden und amöboiden, anbelangt, so könnte man versucht sein, in ihre Erklärung einen elektroosmotischen Vorgang ganz eigener Art einzuführen. Denken wir uns aus dem Plasmabelag einer Pflanzenzelle, in dem, wie gezeigt wird, im allgemeinen die Bedingungen für einen elektroosmotischen Einstrom von Wasser vorliegen, eine Scheibe herausgeschnitten und, ohne daß sie sich veränderte, in Wasser suspendiert, so würde anstelle der erzwungenen Wasserbewegung eine entgegengesetzt gerichtete Bewegung des Protoplasmateilchens eintreten, es würde kraft der sich in ihm abspielenden elektroosmotischen Vorgängen frei durch das Wasser schwimmen. Es ist natürlich der Gedanke zu erwägen, inwieweit derartige Erscheinungen zur Erklärung der Plasmaströmung heranzuziehen sind, vor allem jener einseitig gerichteten Bewegung, wie sie in der Rotation des Plasmas bei Pflanzenzellen auftreten. Die Deutung dieser Erscheinung bereitet erhebliche Schwierigkeiten und ist in befriedigender Weise noch nicht gelungen. Eine Erklärung auf elektroosmotischem Wege wäre möglich; sie würde aber voraussetzen, daß in den strömenden Protoplasmabändern dauernd die Bedingungen für eine einseitige, stets in derselben Richtung erfolgende Bewegung gegeben wären. Es müßte also in dem fließenden Protoplasma eine bestimmt gerichtete polare Struktur erhalten bleiben. Die polare Orientierung der Ströme ist ja die Hauptschwierigkeit für ihre Deutung; die Verlegung, ihrer Ursache in das strömende Protoplasma selbst anstatt in die ruhende Wandschicht, würde mir aber nicht glücklich erscheinen. Man könnte sich ja zur Stütze einer derartigen Theorie auf die flüssigen Kristalle berufen, in denen ja flüssiger Aggregatszustand und polare Orientierung der Teilchen Hand in Hand gehen. Sie weisen aber dafür das Symptom der polaren Struktur auf, das dem fließenden Protoplasma fehlt: die Doppelbrechung, die die plasmatischen Gebilde eben nur dann annehmen, wenn sie relativ fest und stabil werden. Trotzdem ist nicht $z u$ verkennen, daß protoplasmatischen Konvektionsströmen auf elektrischer Grundlage neben dem durch Oberflächenspannung hervorgerufenen Bewegung eine Bedeutung zukommen kann, über deren Maß wir uns z. Zt. allerdings kein Bild machen können.

Nur kurz will ich noch das Problem der Muskelkontraktion streifen. Bei den Widersprüchen, die nicht nur in den Anschauungen, sondern 
auch in den tatsächlichen Angaben über das rein Aeußere des Vorganges, die Formänderungen der an der Bewegung beteiligten Elemente, und über die physiologische Seite, den zeitlichen Zusammenhang der an der Reaktion beteiligten chemischen und elektrischen, thermischen und mechanischen Vorgänge erscheint es mir unmöglich, sich ohne eigene Erfahrung ein Urteil in dieser Frage zu bilden.

Zwei Grundanschaungen stehen sich gegenüber. Die eine erklärt die Muskelkontraktion auf Grund bloßer Formänderung der kleinsten Elemente infolge Aenderung der Oberflächenspannung, die andere nimmt als unmittelbare Ursache der Bewegung Wasserverschiebung infolge verändertem Quellungsvermögens der doppelbrechenden Substanz an. Alle diese Theorien, soweit sie heute diskutiert werden, betrachten den Muskel als chemodynamische Maschine, in welcher chemische Energie in mechanische Arbeit transformiert wird, und zwar durch Konzentrationsänderungen der Stoffwechselprodukte an bestimmten Punkten; wodurch Oberflächenspannung oder Quellungsvermögen eine Veränderung erfahren. Für die energetischen Beziehungen zwischen Stoffwechsel und Leistungen würden sich in all diesen Fällen die gleichen allgemeinen Prinzipien ergeben, von denen am Anfang dieses Abschnittes die Rede war. Die elektrochemischen Erscheinungen würden dabei nur insoweit in Frage kommen, als sie unserer Auffassung gemäß die treibende Ursache des Oxydationsstoffwechsels darstellen.

Ein tieferes Eingreifen der elektroosmotischen Erscheinungen in den Kontraktionsvorgang wäre auf der Grundlage denkbar, daß er auf Wasserverschiebung beruhte, die jedoch nicht infolge von Aenderung des Quellungsvermögens, sondern zwangsweise durch elektroosmotischen Transport stattfände. Eine derartige Theorie läßt sich aber solange nicht begründen, als nicht nachweisbar ist, daß auf diese Weise im Protoplasma die bei der Kontraktion auftretenden Spannungen wirklich erzeugt werden können. Es gilt also hier das Gleiche wie für die Deutung der Variationsbewegungen der Pflanzen, und es kann demnach auf Grund unserer heutigen Kenntnisse eine elektroosmotische Kontraktionstheorie nicht in Frage kommen. Eine andere Schwierigkeit, die ihr entgegenzustehen scheint, wäre meines Erachtens nicht entscheidend: die Deutung des Nutzeffektes der Muskelarbeit, der bekanntlich 30 Proz. und mehr der dabei verbrauchten chemischen Energie betragen kann. Das würde nach unseren auf Seite 290 wiedergegebenen Berechnungen voraussetzen, daß elektrische Spannungen von wenigstens $0,35 \mathrm{~V}$. in Tätigkeit treten, während die kräftigsten wirklich gemessenen Muskelströme 0,1 V. nicht übersteigen. Aber es ist in dieser Hinsicht 
wiederum darauf hinzuweisen, daß die tatsächlich an den plasmatischen Grenzflächen herrschenden Spannungen höher sein müssen, als wir sie im ableitenden Bogen messen. Die Annahme, daß sie unter Umständen Werte von $0,3-0,4 \mathrm{~V}$. erreichen, erscheint mir nicht unmöglịch, jedoch erübrigt es sich, bei der ganzen Lage der Dinge näher auf diesen Punkt einzugehen.

\section{Schlußbetrachtungen.}

Wir haben versucht, in großen Zügen die doppelte Rolle darzustellen, die auf Grundlage der elektrolytischen Atmungstheorie den kapillarelektrischen Vorgängen zuzuschreiben ist: erstens als treibende Kraft der physiologischen Oxydation, zweitens als Mittel zur Energietransformation, das vor allem dann in Wirksamkeit tritt, wenn zwangsweise Verschiebung von Wasser oder gelösten Stoffen zur Erzielung von Sekretions- und Resorptions-Leistungen nötig ist, oder aber in komplizierterer Weise in den Mechanismus chemischer, mechanischer oder formativer Arbeitsleistung eingreift. Naturgemäß ist in Anbetracht unserer mangelhaften Kenntnisse nur ein verhältnismäßig kleiner Teil der Lebenserscheinungen einer so weitgehenden Analyse fähig und ganze Gebiete haben wir vollkommen beiseite lassen müssen, wie z. B. das Problem der Erregungsleitung im lebenden Protoplasma.

Es gibt aber eine gewisse Art von Lebensvorgängen, die sich der energetischen Diskussion entziehen, nicht weil uns die Kenntnis der physiologischen Einzelheiten, sondern die der physikalischen Grundlagen vollkommen fehlt. Um was es sich dabei handelt, ist am einfachsten an einem konkreten Beispiel klar zu machen. Erfolgt auf einer plasmatischen Oberfläche eine chemische Reaktion, so ist ihr Gleichgewicht durch folgende Gleichungen bestimmt:

$$
\text { 1. K. } \mathrm{c}_{1} \cdot \mathrm{c}_{2} \cdot \mathrm{c}_{3} \ldots=1 \quad 2 \cdot \frac{\mathrm{X}_{1}}{\omega}=\alpha_{1} \mathrm{c}_{1}^{\frac{1}{\mathrm{n}_{1}}} \quad 3 \cdot \frac{\mathrm{X}_{2}}{\omega}=\alpha_{2} \mathrm{c}_{2} \frac{1}{\mathrm{n}_{2}} \ldots
$$

1 ist die Gleichgewichtsbedingung der Reaktion in wässeriger Lösung, $2,3, \ldots$ sind die Gleichungen für die Adsorption der einzelnen, an der Reaktion beteiligten Körper, wobei $\mathrm{X}_{1}, \mathrm{X}_{2} \ldots$ ihre Menge anf der Oberfläche $\omega, c_{1}, c_{2}, c_{3}$ ihre Konzentration in der wässerigen Lösung vórstellen, $\alpha_{1}, \alpha_{2} \ldots n_{1}, n_{2} \ldots$ die für die Adsorption eines jeden der Körper geltenden Konstanten. Ist der Prozeß zum Gleichgewicht gelangt, so kann er wieder nach der einen oder nach der anderen Richtung in Gang gebracht werden, sobald aus irgend einer Ursache eine Aenderung der Oberflächenkonzentration irgend eines der reagierenden 
Körper, sei es durch freiwillige Diffusion, sei es durch gewaltsamen, unter Arbeitsaufwand erfolgenden Abtransport, stattfindet.

Das würde den Fall darstellen, den wir oben einer eingehenden Aktivitätsanalyse unterworfen haben. Die Reaktion kann aber gleichermaßen in Gang gebracht werden, wenn irgend eine der Oberflächenkonstanten in den Gleichungen 1,2 . . eine Aenderung erfähtt. Solche Vorgänge aber spielen im Leben des Organismus eine ganz hervorragende Rolle.

Am augenfälligsten kommen sie zum Ausdruck in der Bildung von Abwehrfermenten und Immunkörpern: Hierbei treten unter dem EinfluB körperfremder Substanzen entweder Stoffe mit neuen bisher nicht vorhandenen Affinitäten auf - mögen wir nun diese als chemischer oder adsorptiver Natur betrachten - oder es wird, wie bei den "hervorgelockten" Fermenten im Sinne Röhmanns die Bildung bestimmter Stoffe stark gefördert. Das Auffällige daran ist die Tatsche, daß die so erzeugten Affinitäten sich gerade auf die Körper richten, die die physiologische Reaktion auflösen. Irgend eine nähere Vorstellung über den Mechanismus dieser Leistung können wir uns nicht machen; wir können nur das eine sagen, daf Arbeitsleistung notwendig ist, wenn das Substrat in Gegenwart eines Körpers so verändert wird, daß eine Affinität zu diesem Stoff entsteht. Denn es wird dadurch ein arbeitsfähiges Potential geschaffen, das sich durch Absättigung dieser Affinität betätigt. In welcher Weise aber die Arbeitsleistung erfolgt, davon haben wir auch nicht die geringste Vorstellung.

Das aber können wir mit Bestimmtheit sagen, daß die erwähnten Erscheinungen nur das augenfälligste Beispiel für einen weit verbreiteten Vorgang sind. Er tritt uns, wenn auch nicht mit gleicher Schärfe in den Funktionen der Resorption und Sekretion entgegen, wir beobachten ihn z. B. in ganz auffallender Weise an der Niere, deren komplizierte Tätigkeit die Partialfunktionen der einzelnen Elemente so zusammenwirken, daß „dem Blut eine konstante $\mathrm{Zu}$ sammensetzung verliehen wird. Hierfür sind ihre Zellen befähigt, selektiv gerade diejenigen Stoffe an sich zu reißen und zu transportieren die in einer von der Norm abweichenden Menge im Blut vorhanden sind". So charakterisiert Höber (loc. cit. S.660) die Tätigkeit der Niere, die auf Schritt und Tritt ein veränderliches Verhalten über Elemente gegenüber den gelösten Stoffen des Blutes erkennen läßt, wofür Höber einige Beispiele anführt: „Während die Niere trotz des Gehaltes des Blutes an gelöstem Traubenzucker gewöhnlich keinen oder doch so gut wie keinen Zucker in den Harn abscheidet, braucht 
nur der Zuckergehalt des Blutes etwas zu steigen, damit gleich mehrere Prozent Zucker im Harn auftreten oder: Wenn man ein Tier möglichst chlorfrei ernährt, so produziert es trotz reichlichem Gehaltes an Kochsalz im Blut einen fast oder ganz chlorfreien Harn." Das sind Erscheinungen, die letzten Endes auf irgend welche Affinitätsänderung zwischen der lebenden Substanz und den gelösten Stoffen hinauslaufen müssen. Aehnliches köunen wir auch an der Pflanzenzelle beobachten. So bilden, wie schon lange bèkannt ist, chlorophyllhaltige Zellen im Dunkeln Stärke aus Rohrzucker, der ihnen in der Außenlösung geboten wird; also muß der Zucker in die Zelle eindringen, und doch kann man mit Hilfe der gleichen Rohrzuckerlösung die Zelle dauernd plasmolysieren, also wird die Permeabilität des Protoplasmas vor Erreichung des Diffusionsgleichgewichtes aufgehoben. Tatsächlich läßt sich zeigen, daß, wenn man Pflanzengewebe in Salzlösungen legt, das Salz anfangs rasch eindringt, sehr bald aber und lange vor Erreichung des' Diffusionsgleichgewichtes dieser Vorgang sistiert wird ${ }^{1}$ ).

Auch hier handelt es sich um Vorgänge, die wie die Immunitätsreaktion durch Anwendung körperfremder Substanzen hervorgerufen werden. Es kann aber keinem $Z$ weifel unterliegen, daB auch im normalen Umsatz der Zelle dergleichen vorkommt und bei der Regulation von Stoffwechsel und Stoffaustausch eine große Rolle spielt.

Schließlich haben wir allen Grund zur Annahme, daß derartige Affinitätsänderungen auch in die formativen Prozesse eingreifen. Bei der bereits oben erwähnten Bildung geformter Sekrete tritt nämlich vielfach in rhythmischem Wechsel irgendeine Funktionsänderung der sezernierenden Zellen auf, der sich in einem geschichteten Bau der Ausscheidungen äußert, gleichviel ob wir Stärkekörner, Zellmembranen oder Zellen ins Auge fassen. Sicherlich sind diese Funktionsänderungen auf die beschriebenen Aenderungen von Oberflächenaffinitäten zurückzuführen. Vielleicht wird das systematische Studium dieser Konstanten und ihrer. Veränderlichkeit bei leblosen Kolloiden einige Aufschlüsse bringen, die für die Biologie von Wichtigkeit wären. Denn ein Teil der rätselhaftesten Lebenserscheinungen steht damit im Zusammenhang.

1) Vgl. A. Nathansohn, Stoffwechsel der Pflanzen, S. 97, und die dort zitierte Kontroverse über diesen Gegenstand; H. Fitting, Jahrb. f. wiss. Bot. 56 (1915) u. 57 (1916); A. Tröndle, Arch. de Soc. phys. et nat. [4] 45 (1918). 